\title{
Location of cation impurities in NGRIP deep ice revealed by cryo-cell UV-laser-ablation ICPMS
}

\author{
Damiano DELLA LUNGA, ${ }^{1}$ Wolfgang MÜLLER, ${ }^{1}$ Sune Olander RASMUSSEN, ${ }^{2}$ \\ Anders SVENSSON ${ }^{2}$ \\ ${ }^{1}$ Department of Earth Sciences, Royal Holloway University of London, Egham, Surrey, UK \\ E-mail: damiano.dellalunga.2011@live.rhul.ac.uk \\ ${ }^{2}$ Centre for Ice and Climate, Niels Bohr Institute, University of Copenhagen, Copenhagen, Denmark
}

\begin{abstract}
In polar ice sheets, the average grain size varies with depth. Ice grain size increases due to several factors including ice temperature and impurity content, which in turn varies with climate. The effect of impurities on grain growth is thought to be crucial but has never been observed experimentally. Using a methodology recently developed at Royal Holloway University of London, in situ chemical analysis of frozen ice at sub-ppm concentrations with unprecedented spatial resolution $(\sim 150 \mu \mathrm{m})$ is achievable using ultraviolet laser ablation inductively coupled plasma mass spectrometry (UV-LA-ICPMS) featuring a two-volume cryo-LA-cell. Following surface cleaning with a custom-built vice equipped with a ceramic blade, NGRIP ice slabs ( 86 ka before AD 2000) have been analysed using a series of one-dimensional profiles and two-dimensional maps of laser spots at a resolution of 200$300 \mu \mathrm{m}$. Results demonstrate that cation impurities are not uniformly distributed in ice layers and show significant variations in concentration on a sub-millimetre scale. Furthermore, a different pattern of elemental distribution between clear ice and layers enriched in impurities (cloudy bands) has been identified: while concentration differences for cloudy bands are not resolvable between boundaries and inner grain domains, within clear ice, grain boundaries and junctions are significantly (up to 100 times) impurity-enriched relative to corresponding grain interiors.
\end{abstract}

KEYWORDS: crystal growth, glaciological instruments and methods, ice chemistry, ice core, ice crystal studies

\section{INTRODUCTION}

Ice cores from ice sheets are a valuable archive of palaeoclimatic information. Traditionally, most of the information about past climate comes from water isotopes, air bubbles trapped in the ice and chemical analyses. Changes in grain size appear to be associated with climatic events, which were early on observed at the transition between the Holocene and the Last Glacial Maximum (LGM) in the Dome C ice core from Antarctica (Duval and Lorius, 1980). Since then, this generally sharp grain-size decrease has also been observed for termination I and II in the EPICA Dome C core from Antarctica (Durand and others, 2006), the Greenland Ice Sheet 2 (GISP2) ice core (Gow and others, 1997), the Greenland Ice Core Project (GRIP) ice core (Thorsteinsson and others, 1995, 1997) and the NorthGRIP (NGRIP) ice core (Wang and others, 2002). The relationship between grain size and climatic changes may be assigned to ice microstructure dynamics (Durand and others, 2006), which include migration of grain boundaries by soluble impurities (Alley and Woods, 1996), pinning by insoluble microparticles (Jun and others, 1998) or a conditioning of surface temperature at the moment of deposition (Petit and others, 1987). Since many ice-core parameters (e.g. water isotope record, impurity concentration and dust particle concentration) show abrupt changes at climatic transitions, it is difficult to establish what governs the observed grain-size changes across such transitions.

The objective of this paper is to assess the influence of impurities on ice grain growth and/or recrystallization through the identification of the location of cation impurities and the distribution of these between inner parts of grains and grain boundaries. In fact, the location of impurities in the ice lattice of the large ice sheets is still a matter of debate and, although it is generally assumed that trace constituents tend not to be confined uniquely to grain boundaries, this assumption has never been confirmed beyond doubt in experiments (Ohno and others, 2005). To confirm or disprove this assumption - using an in situ technique with sub-ppm detection limits such as ultraviolet laser ablation inductively coupled plasma mass spectrometry (UV-LAICPMS) directly in frozen ice cores - is the main aim of the present work.

Grain growth is generally assumed to be slowed by the interaction of grain boundaries with microparticles and impurities (Alley and others, 1986). Microparticles such as dust are generally micrometer-sized and thus much larger than ionic impurities which may diffuse and possibly move into the ice lattice, whereas dust cannot. In a so-called 'lowvelocity regime', the force that drives the migration of grain boundaries is not large enough to force apart microparticles or impurities, which therefore tend to lie on grain boundaries (Alley and others, 1986). In contrast, in a 'high-velocity regime', the grain boundaries migrate more rapidly than the extrinsic material (particles or impurities) which will lie in the inner part of the ice grain more frequently compared to the low-velocity regime (Alley and others, 1986). It is generally assumed that polar ice is in a low-velocity regime compared to soluble particles, and in a high-velocity regime compared to microparticles and dust (Alley and others, 1986). Impurity records can be applied for the identification of annual layers in ice cores, since seasonally varying impurity compositions can often be observed, which for 
Holocene ice in Greenland include a sea-salt peak ( $\mathrm{Na}, \mathrm{Mg}$ ) in late winter, followed by a dust peak $(\mathrm{Ca}, \mathrm{Al}, \mathrm{Fe})$ in spring and enhanced $\left[\mathrm{SO}_{4}\right]^{2-},\left[\mathrm{NO}_{3}\right]^{-}$and $\left[\mathrm{NH}_{4}\right]^{+}$during summer (Rasmussen and others, 2006). During glacial periods, however, all impurity peaks may coincide (Andersen and others, 2006).

The impurity content is therefore crucial in order to reconstruct the climate variability at high resolution. Moreover, the location and distribution of these soluble and insoluble impurities inside grains of deep ice cores provide important information about the occurrence of ice recrystallization, grain growth and deformation at various depths.

In this paper, we present the first attempt to analyse chemically at the sub-ppm level the nature, location and distribution of microparticles and impurities within two different domains of glacial ice samples directly in the frozen state with sub-millimetre resolution via cryo-cell UV-LA-ICPMS (Müller and others, 2011), with a specific focus on areas with either high amounts of impurities or areas with a strong concentration gradient.

The investigated samples are taken at depths of $\sim 2700 \mathrm{~m}$ from the NGRIP ice core (NorthGRIP Members, 2004) where the ice has an age of $\sim 86 \mathrm{kab} 2 \mathrm{k}$ (thousand years before AD 2000).

\section{IMPURITIES IN ICE}

Snow falling over Greenland generally contains low amounts of impurities, since most of them have been removed already by precipitation or fallout during transport from the sources to the pole. Nevertheless, $\sim 80 \%$ of all precipitation over the poles nucleates on dust or aerosol particles (Barnes and Wolff, 2004). Furthermore, the majority of the impurities are attached or embedded in snowflakes, but not necessarily as a nucleus (Fischer and others, 2007).

Impurities include dust particles, acids and ash from volcanoes, sodium and chloride ions (indicators of sea-ice extension), ammonium (related to forest wildfires), and lead, sulphate and nitrate from human pollution. All are indicators of past climate or environment. Their distribution plays a crucial role in determining most of the physical properties of ice and has implications for the mobility of chemical species after deposition, as well as conductivity, via the interaction between different components trapped in ice (Rempel and others, 2001, 2002).

Ice-core impurities can be divided into soluble and insoluble fractions. The soluble impurities include chemical compounds of marine, terrestrial and biogenic origin such as $\mathrm{Na}^{+}, \mathrm{K}^{+}, \mathrm{NH}^{+}, \mathrm{Mg}^{2+}, \mathrm{Ca}^{2+}, \mathrm{NO}^{3-}, \mathrm{SO}_{4}{ }^{2-}$ and $\mathrm{Cl}^{-}$(Legrand and Delmas, 1988). The insoluble impurities include microparticles of terrestrial origin that are often referred to as 'dust' (e.g. Steffensen, 1997).

Polar ice continually recrystallizes even at constant temperature and under zero stress/strain conditions (Faria and others, 2014). The analysis of grain size and c-axis orientation vs depth in Antarctic cores (e.g. the Byrd deep ice core) suggested that three main recrystallization regimes affect the microstructural evolution of ice grains (Stephenson, 1967; Gow, 1969; Alley and others, 1986, Durand and others, 2006). According to these authors, for the uppermost $\sim 400-700 \mathrm{~m}$ of the ice, grains linearly increase their average size in a process called 'normal grain growth'. Below this depth the increasing strain in the ice sheet was thought to occur via rotation recrystallization, a process that involves the rotations of subgrains and the migration of subgrain boundaries across regions with lattice curvature, eventually outlining a new boundary between two different grains. In the very deep part of the ice sheet (bottom $\sim 150 \mathrm{~m}$ ), 'migration recrystallization' might take place, when entirely new grains are formed and boundaries migrate very fast. This so-called 'tripartite paradigm' has recently been challenged (Kipfstuhl and others, 2006, 2009) through a detailed microstructure study of Antarctic ice and firn at EPICA Dome $C$ and EPICA-DML. At these two sites the authors found evidence of migration and rotation recrystallization at very shallow depths, where these mechanisms appear to be dominant. Computer simulation and laboratory experiments on normal grain growth have also raised doubts about the tripartite paradigm, showing that shallow polar ice cores are characterized by microstructures affected by processes other than normal grain growth, i.e. dynamic recrystallization (Faria and others, 2014).

In general, it is assumed that ice grain growth is influenced by impurities and the relation describing grain boundary velocity $v$ can be written as (Alley and others, 1986)

$$
v=\mu P
$$

where $\mu$ is the grain mobility and $P$ is the driving force for grain boundary migration, which, for normal grain growth, can be defined as (Alley and others, 1986)

$$
P=\frac{2 \gamma}{R^{\prime}}
$$

where $\gamma$ is the surface tension and $R^{\prime}$ is the radius of curvature of a spherically curved section of grain boundary that migrates.

Alley and others (1986) derived the following relationship for the grain boundary drag effect of microparticles:

$$
\frac{P_{\mathrm{p}}}{P_{\mathrm{i}}}=\frac{9 V_{\mathrm{p}} R}{4 r_{\mathrm{p}}}
$$

where $P_{\mathrm{p}}$ is the drag force due to microparticles, $P_{\mathrm{i}}$ is the intrinsic driving force for grain growth, $V_{p}$ is the volume fraction of particles, $R$ is the average grain radius and $r_{\mathrm{p}}$ is the particle radius. The model predicts an increased drag effect $P_{\mathrm{p}} / P_{\mathrm{i}}$ with higher volume concentrations and small particle size, and with larger grain sizes. However, the growth rate reduction calculated from Eqn (3) for termination I and II in GRIP ice has been found to be far too low to be responsible for the observed grain-size reduction (Thorsteinsson and others, 1995). Weiss and others (2002) also found, in the EPICA Dome C core, that high soluble impurity content does not necessarily imply a slowing-down of grain growth kinetics, whereas the pinning of grain boundaries by dust particles could explain, in some cases, the change of the ice microstructure.

Guillope and Poirier (1979) had previously considered two possible avenues for grain boundary migration when impurities are present: (1) slow migration of the boundary when it is unable to break away from the impurities and must drag them along with it as it migrates, and (2) fast migration of the boundary, when the driving force for migration is sufficient to overcome impurity drag, and the boundary can break away from the pinning effect of the impurities. Factors that can trigger the sudden jump to fast migration include higher temperature and higher misorientation across a boundary, both increasing the grain boundary mobility. 
The identification of the dominant mechanism of grain growth and recrystallization in polar ice has been discussed over many years. Although some models (Durand and others, 2006, 2009), taking into account recrystallization processes and effects of impurities, were able to reproduce the grain-size variations for the first $\sim 2000 \mathrm{~m}$ of core (EPICA Dome C), below this depth the observed grain size was greater than the model predicts, meaning that the modelled pinning effect was too strong. A better reproduction of the evolution of grain size with depth in EPICA Dome $C$ has been achieved implementing a thermally activated unpinning effect (Durand and others, 2009), which, however, cannot describe accurately the amplitude of decreases in grain size during climatic transitions below $2200 \mathrm{~m}$ depth. This might be due to the establishment of equilibrium between the unpinning effect induced by temperature on particles, and the pinning effect that can act again on the same particles through the effect of grain growth (Durand and others, 2009).

From the brief overview above, it is clear that the location and distribution of soluble and insoluble impurities in ice, and especially in deep ice cores, is still largely unclear, as is the effect of microparticles on grain-size variation.

Several in situ analyses of impurities in polycrystalline ice have been carried out in the past: Mulvaney and others (1988) used cryo-SEM and X-ray analysis of Antarctic samples to detect sulphur (reported detection limit 490 ppm; Mulvaney and others, 1988), whose contribution was thought to be entirely from sulphuric acid. Sulphur was found to be located preferentially at triple junctions, as confirmed by other studies on Antarctic samples with Raman spectroscopy, but also in liquid veins (Fukazawa and others, 1998). On the other hand, Cullen and Baker (2000, 2001) observed that the majority of impurities in the GISP2 core and in the Antarctic Byrd core are not trapped in two-grain boundaries or triple junctions. Using scanning electron microscope (SEM)/energy-dispersive spectroscopy (EDS) microscopy, Baker and Cullen (2003) observed filaments in grain boundaries, and impurity spots in grain interiors. They concluded that, although the filaments are an artefact produced by the sample sublimation, they demonstrate the presence of impurities segregated along boundaries. They also concluded that impurity spots in grain interiors reside there and are not transported during specimen preparation or observation. In the less recrystallized Holocene ice, Barnes and Wolff (2004) performed SEM X-ray analysis on ice from four different polar sites, concluding that impurities are present in a wide range of locations, which include triple junctions, grain boundaries, lattice and vapour/solid interfaces (estimated detection limit 2-5 ppm for S, Na, Mg and Cl; Barnes and Wolff, 2004). lizuka and others (2004) performed ion chromatography at $2 \mathrm{~mm}$ resolution on Holocene ice at Dome Fuji, concluding that coexistence of specific cation-anion pairs could lead to different distributions of soluble impurities in the ice microstructure. In fact, $\mathrm{Na}^{+}$was found to be related to $\mathrm{Cl}^{-}$(mainly from sea-salt input) with no preferential distribution between boundaries and interiors, whereas $\mathrm{Mg}^{+}$largely coexisted with $\mathrm{SO}_{4}{ }^{2-}$, which has been observed preferentially at triple junctions (Mulvaney and others, 1988; Fukazawa and others, 1998). However, Ohno and others (2005) analysed ice from Dome Fuji, for a range of Holocene depths using micro-Raman spectroscopy, concluding that most sulphate and soluble impurities were trapped in inclusions within the grains as sulphate salts, which are not affected by alteration or diffusion after deposition, thus preserving the climate-related signal. According to Durand and others (2006) the grain-size decreases associated with glacial periods in EPICA Dome C are mainly the result of pinning by dust particles located along grain boundaries. X-ray tomography of LGM samples of the same core showed that the largest dust particles were concentrated along grain boundaries (Durand and others, 2006). This conclusion has recently been taken as evidence for the faster densification observed in impurity-rich layers of polar firn (Hörhold and others, 2012). Obbard and Baker (2007) used ion chromatography and SEM microscopy-Xray spectroscopy to determine the type and location of impurities over a range of depths along the entire Vostok ice core. They concluded that the high dust content, while positively correlated with small grain size, was not the cause of it, and the large particles observed were always within the grain interiors and never on boundaries. However, they observed the occurrence of high concentrations of $\mathrm{Ca}^{+}$along boundaries in glacial ice, and concluded that over a certain critical concentration $\mathrm{Ca}^{+}$decreased grain boundary mobility, leading to an abnormally small grain size. These findings agree with lizuka and others (2008), who performed ion chromatography and Raman spectroscopy on Dome Fuji and GRIP samples over a wide range of depths to determine the relationship between ion balance and the chemical compound of salt inclusions, showing that most of the impurities were not aligned on grain boundaries. Using micro-Raman spectroscopy and energy-dispersive X-ray spectroscopy, Sakurai and others $(2009,2010)$ determined that micro-inclusions tend to group together in small clusters, rather than being evenly distributed in the ice grains. However, the distribution of these clusters was not influenced by grain boundaries.

Reinhardt and others (2001, 2003) applied infrared (IR)-LA-ICPMS to deep GRIP and NGRIP samples to demonstrate the positive linear relationship between the concentration of elements such as $\mathrm{Na}, \mathrm{Mg}, \mathrm{Al}, \mathrm{Fe}$ and particle concentration (measured by laser scattering), concluding that elements were bonding to particulate matter (reported detection limit $0.1-1 \mu \mathrm{g} \mathrm{kg}^{-1}$; resolution $4 \mathrm{~mm}$; Reinhardt and others, 2003).

\section{RECRYSTALLIZATION AND INTEGRITY OF NGRIP CORE}

The stratigraphy of the NGRIP ice core (NorthGRIP Members, 2004) is generally regarded as remarkably well preserved (Svensson and others, 2005). It is visible to the naked eye throughout the last glacial period, with high dust concentrations and many bright layers (so-called cloudy bands) which occur during the coldest events. The horizontal layering is recognizable by cloudy bands formed by particle-enriched layers alternating with clear ice layers. In general, the cloudy bands are characterized by small ice grain sizes whereas the clear ice contains crystals up to a factor of 10 larger (Svensson and others, 2005).

Down to $2600 \mathrm{~m}$ depth the horizontal layering is highly regular and undisturbed. Below this depth, cloudy bands develop mm-sized undulations, together with layers inclined up to $15^{\circ}$. However, it is just below $2800 \mathrm{~m}$ that the visual stratigraphy becomes more uncertain, since the record is penetrating into climatically and physically warmer ice, due to heat flux from the bedrock. 
Inclined, folded and wavy strata are known to affect dielectric profiling (DEP) and continuous flow analysis (CFA), because they mix the signal that is a result of an average over a cross section of the core (Faria and others, 2010). The problem is especially important in the case of CFA since the rate of melting of an ice-core slab is sometimes not constant and the continuous collection of meltwater by the melting head and the distribution through capillaries to the sensors are occasionally discontinuous, introducing other small alterations to the climate signal (Faria and others, 2010). Due to a much smaller sampling area and sub-mm acquisition, UV-LA-ICPMS is not affected by these problems and facilitates chemical detection of different layers even when the layer thickness approaches the physical limit of CFA resolution (up to $\sim 10 \mathrm{~mm}$; Bigler and others, 2011), as in the case of our samples whose reported layer thickness is $\sim 12 \mathrm{~mm}$ (Vallelonga and others, 2012).

Among the processes mentioned in the previous section for ice recrystallization, normal grain growth and rotation recrystallization do not affect the palaeoclimatic signature or the impurity distribution except at a $\mathrm{mm}$ scale (Duval and others, 2012). According to Faria and others (2010), there is hardly any interaction between visible micro-inclusions and grain boundaries down to $2500 \mathrm{~m}$ depth at EPICA-DML, whereas the deeper ice seems to 'harvest' micro-inclusions. The cause of this phenomenon is still a matter of research, and it may be related to changes in the internal structure of grain boundaries in response to a temperature increase (Azuma and others, 2012). It has been proposed that the activation energy for grain boundary diffusion may be larger than that for lattice diffusion, suggesting that grain boundaries could be either in solid amorphous state or have a quasi-liquid structure, where water molecules are jammed (Faria and others, 2014). This would significantly affect the grain boundary energetics and therefore the regime of interactions between grain boundaries and impurities.

After comparing the visual stratigraphy profiles of EDML (Fig. 1a, from Faria and others, 2010) and NGRIP (Fig. 1b, from Svensson and others, 2005) we conclude that the original stratigraphy is well preserved at the NGRIP site at the studied depths of 2695-2720 m, and dynamic recrystallization, if present, has a negligible effect on the impurities redistribution. Moreover, although some mm-sized deformation is occasionally evident (Fig. 1b), the observable deformation is probably related to the large-scale dynamics of the ice sheet, which will not significantly affect the relative position of impurities in the ice, so that our samples have essentially preserved the conditions at the time of the closure of the system (i.e. firn-ice transition at $\sim 100 \mathrm{~m}$ depth).

\section{MATERIALS AND METHODS}

Samples from the NGRIP ice core were cut at the ice repository at the Centre for Ice and Climate, Niels Bohr Institute, Copenhagen. The cryo-cell sample holder is able to hold, simultaneously, up to three ice volumes $(50 \mathrm{~mm}$ length $\times 11 \mathrm{~mm}$ width $\times 11 \mathrm{~mm}$ depth). For this study, five ice strips of such dimensions from NGRIP, labelled as 4899_A7, 4899_B8, 4900_A5, 4946_B4 and 4882_B5 from depth intervals 2694.1-2694.15 m, 2694.025-2694.075 m, 2694.75-2694.8 m, 2720.075-2720.075 m and 2684.825$2684.875 \mathrm{~m}$ respectively, were chosen, representing an age range of $\sim 84.4-87.8 \mathrm{ka} \mathrm{b} 2 \mathrm{k}$. All samples correspond to a few years each, given the layer thickness of $\sim 12 \mathrm{~mm}$

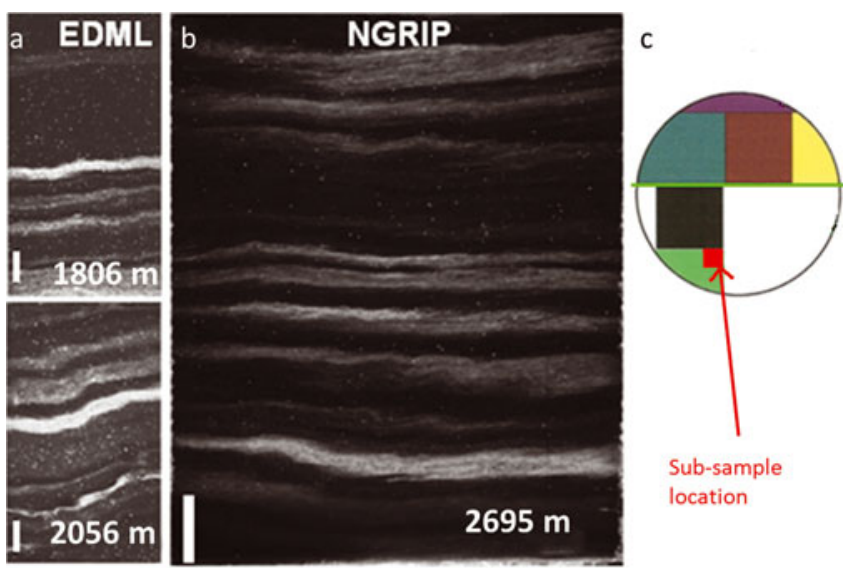

Fig. 1. Visual stratigraphy comparison between (a) EPICA-DML, from Faria and others (2010), and (b) NGRIP, from Svensson and others (2005). The methodology used to acquire these pictures is described in detail by Svensson and others (2005). Depth (m) is indicated at the bottom right. All scale bars are $1 \mathrm{~cm}$. The occurrence of wavy layers and $\mathrm{mm}$-scale folds that takes place between 1800 and $2050 \mathrm{~m}$ at EDML is less pronounced at NGRIP, which is well preserved at the depth shown $(\sim 2700 \mathrm{~m})$ and below. (c) Sketch of the NGRIP cross section with subsamples utilized for the present study, indicated by a red arrow. The green line represents the cut surface analysed for visual stratigraphy as in Svensson and others (2005)

(Vallelonga and others, 2012), and overall cover the ending, beginning and middle part of Greenland Stadial 22 (i.e. the 'cold' part of Dansgaard-Oeschger event 22), whose duration exceeds 3000 years (Vallelonga and others, 2012).

A careful spatial referencing of the samples with images of the core, taken by Svensson and others (2005), was carried out to provide a mm-to-mm match between scan pictures and acquisition grids of laser spots via UV-LAICPMS. Knowing the exact depth interval of the sample and the subsample location, the corresponding section of the core scan was located by counting pixels on the image of the corresponding NGRIP bag.

Cleaning of the ice surface was conducted using a ceramic Y-doped $\mathrm{ZrO}_{2}$ blade (American Cutting Edge, USA), mounted on a custom-built PTFE vice that allows surface smoothing and ice scratching in steps of $<0.5 \mathrm{~mm}$ in order to remove contamination from cutting (Fig. 2c). The blade was analysed by LA-ICPMS to quantify the presence of metals and to assess eventual contamination of ice; its composition is $96.9 \% \mathrm{Zr}, \sim 3 \% \mathrm{Y},<0.1 \% \mathrm{Al},<10 \mathrm{ppm}$ of $\mathrm{Fe}, \mathrm{Cu}, \mathrm{Mg}$, Ca. Approximately $2 \mathrm{~mm}$ of ice were removed from all surfaces about to be analysed, which correspond to the upwardfacing surface of the section of NGRIP ice core utilized. A sketch of the cross section of the NGRIP core with an indication of the section utilized for the present study is provided in Figure 1c.

The methodology used for these analyses is modified here from Müller and others (2009, 2011). The RESOlution M-50 excimer (ArF, $193 \mathrm{~nm}$ ) laser system (prototype) at Royal Holloway University of London (RHUL) is coupled with an Agilent 7500cs ICPMS operated in collision/reaction cell mode (Fig. 2a). A unique, specifically designed cryo-sample holder (Laurin Technic, Australia) made of anodized aluminium capable of keeping up to three strips of $50 \mathrm{~mm}$ long ice core $\left(<12 \mathrm{~mm}\right.$ thick, $<13 \mathrm{~mm}$ wide) below $-15^{\circ} \mathrm{C}$ is compatible with the Laurin two-volume LA cell (Fig. 2d). 


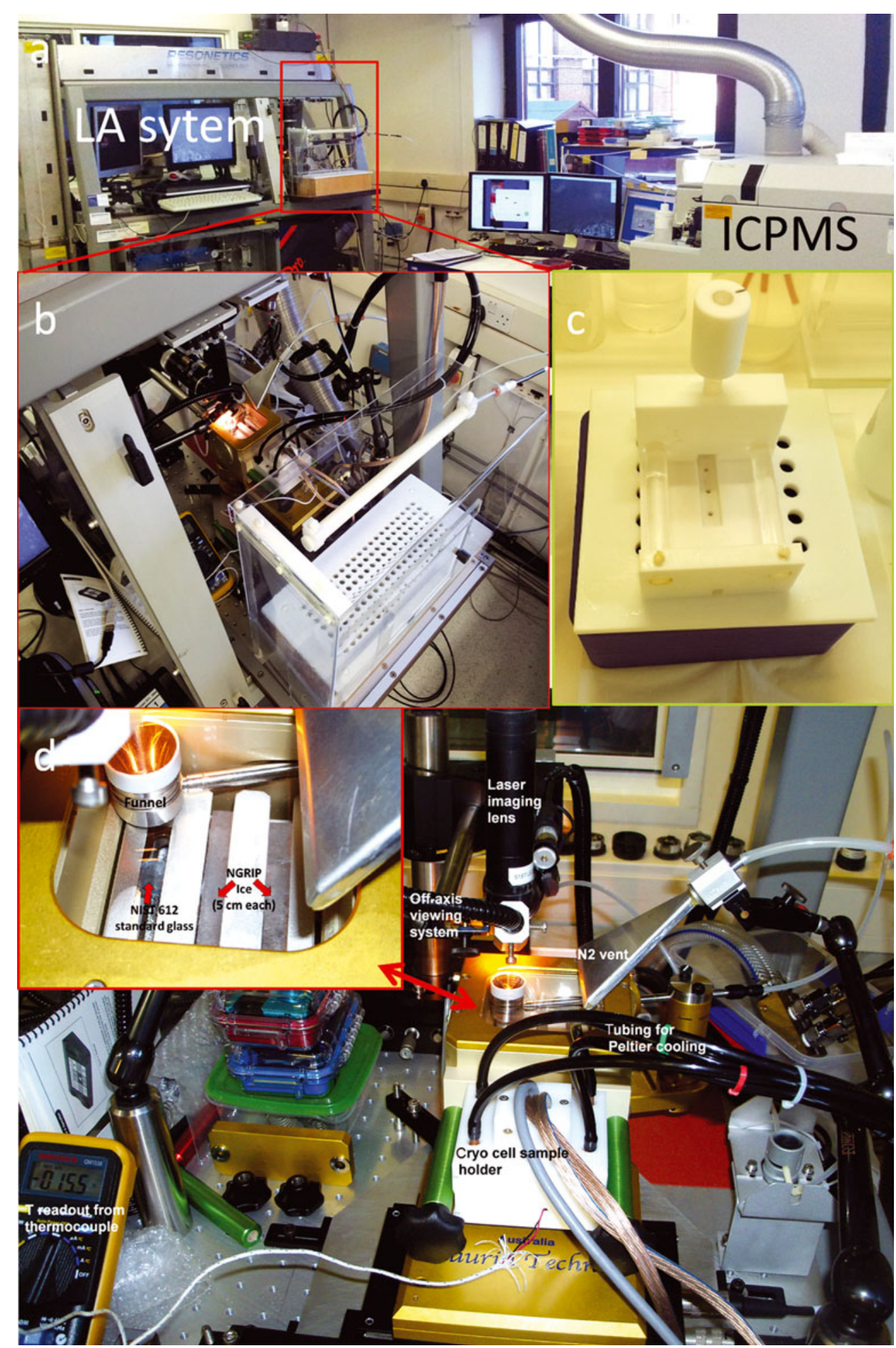

Fig. 2. Photographs of the UV-LA-ICPMS system when operating for ice analysis. (a) The laser-ablation system (left) is coupled with an Agilent 7500cs quadrupole ICPMS (right). The red inset (b) shows a close-up of the work surface in front of the LA cell, which comprises a polyurethane cool box covered with a clear plastic hood. This represents the sample-loading area. The cool box is filled with liquid $\mathrm{N}_{2}$ which cools the air above, and $\mathrm{N}_{2}$ blown in from the top of the hood (white PTFE cylinder) preserves a dry atmosphere in the loading area and prevents frosting of samples during loading procedures. (c) Custom-built PTFE vice for ice scraping, in a clean laboratory (class 100) workstation. The purple reservoir contains liquid $\mathrm{N}_{2}$, which is used to cool the overlying PTFE lid and vice. (d) Close-up of the LA-cryo-cell.

PTFE-coated Cu-Be springs are used to lift the ice volumes against the reference surface of each slot, so that the ice is held in position firmly and evenly. The cool side of a Peltier element, powered by a low-voltage power supply, is used to cool the cell, while the warm side of the same Peltier element is cooled in turn by filtered cooling water.
The laser beam passes through a motorized aperture mask wheel with 12 round apertures allowing selection of circular spot sizes between 7 and $300 \mu \mathrm{m}$, or via a variable rotating rectangular aperture; a demagnified image of the chosen aperture size is imaged and focused onto the sample surface. Large spot sizes, typically between 280 and 

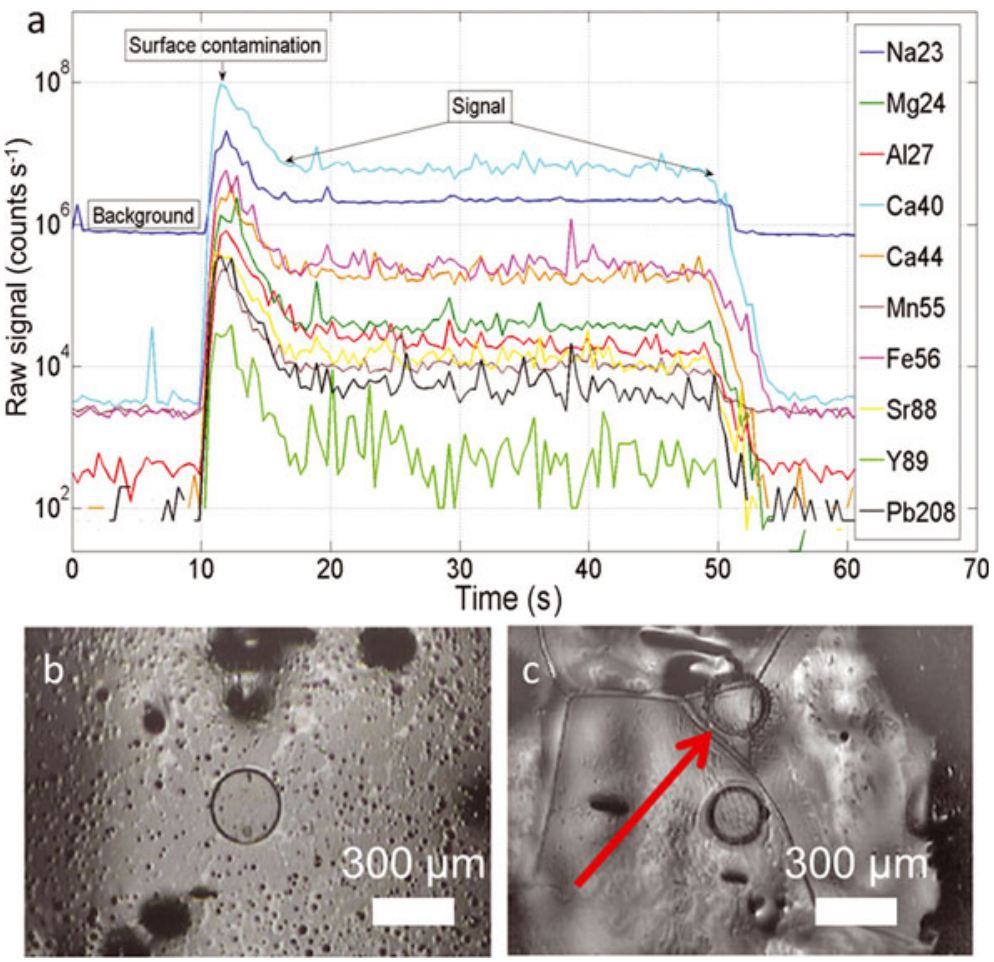

Fig. 3. (a) Raw intensities of a single spot drilling, seen in (b) (laser spot $280 \mu \mathrm{m}$ ). Ablation time $40 \mathrm{~s}+20 \mathrm{~s}$ background. The data reduction includes subtraction of background and removal of surface contamination. (b) Laser crater, $280 \mu \mathrm{m}, 20 \mathrm{~Hz}$. (c) Laser craters at $280 \mu \mathrm{m}$, $20 \mathrm{~Hz}$ : the crater shape is not affected by drilling on boundaries or triple junctions, as indicated by the arrow.

$128 \mu \mathrm{m}$, are needed to detect concentrations of major cations in Greenland ice, which are at sub-ppm level.

The absorption coefficient of ice shows a sharp increase from $250 \mathrm{~nm}$ to $175 \mathrm{~nm}$ of $\sim 10$ orders of magnitude (Warren and Brandt, 2008), with ice at $193 \mathrm{~nm}$ having a relatively low absorption coefficient of $\sim 0.1 \mathrm{~cm}^{-1}$. At a wavelength of $193 \mathrm{~nm}$ we estimate a removal of $\sim 0.1-$ $0.15 \mu \mathrm{m}$ of ice per laser pulse at fluences (laser energy per unit area on the work material) of $\sim 3 \mathrm{~J} \mathrm{~cm}^{-2}$ (Müller and others, 2011), 5000 times less than the $\sim 30 \mu \mathrm{m}$ removed per pulse by IR-LA on ice, which uses much higher laser energies (Reinhardt and others, 2001). Lower fluences, which are kept constant by preventing frosting over the cell window from air humidity with a small $\mathrm{N}_{2}$ vent, provide a more controlled ablation and create craters of smooth circular shape (Fig. $3 \mathrm{~b}$ and c).

A custom-built cryo-worksurface $(\sim 45 \mathrm{~cm} \times \sim 20 \mathrm{~cm})$ can be attached to the LA system to help with sample loading; a polyurethane cool box $(\sim 40 \mathrm{~cm} \times \sim 16 \mathrm{~cm})$ is filled with liquid nitrogen and covered with a PTFE lid (Fig. $2 \mathrm{a}$ and b). A regular grid of $0.8 \mathrm{~cm}$ holes in the lid allows the liquid nitrogen to cool air above the PTFE surface down to $-20^{\circ} \mathrm{C}$ for $>1$ hour. This permits the safe handling of ice samples in the vicinity of the cell and facilitates loading procedures. Nitrogen is blown over the top of the lid and the whole cool box is covered by a clear plastic hood that keeps a cold, clean and dry atmosphere around the holder during the loading procedures, preventing frosting-over of samples and allowing the user to access the inside via plastic flaps from the sides of the hood (Fig. 2b).

A He flow $\left(850 \mathrm{~mL} \mathrm{~min}^{-1}\right)$ inside the LA cell carries ablated particles to the ICPMS and is mixed downstream with $650-700 \mathrm{~mL} \mathrm{~min}^{-1}$ of $\mathrm{Ar} . \mathrm{H}_{2}\left(8 \mathrm{~mL} \mathrm{~min}^{-1}\right)$ was also added downstream to enhance the sensitivity of low-mass elements. The Agilent 7500 ICPMS has been fitted with a cs-lens that allows better low-mass enhanced tuning, and it was operated in collision/reaction cell mode. Plasma-based interferences such as ${ }^{40} \mathrm{Ar}$ and ${ }^{40} \mathrm{Ar}^{16} \mathrm{O}$ are removed inside the collision cell by adding $4.5 \mathrm{~mL} \mathrm{~min}^{-1}$ of $\mathrm{H}_{2}$, allowing measurements of mass 40 and 56 ( $\mathrm{Ca}$ and Fe respectively) at the lowest ppb concentration levels, since ${ }^{40} \mathrm{Ar}$ and ${ }^{40} \mathrm{Ar}^{16} \mathrm{O}$ undergo charge transfer reaction inside the cell (McCurdy and Woods, 2004). KED lens tuning between OctP, QP bias and QP focus has been set (Table 1). Typical limits of detection (LODs) for $\mathrm{Na}, \mathrm{Mg}, \mathrm{Al}, \mathrm{Ca}$ and $\mathrm{Fe}$, measured using NIST 612 standard glass, are 100, 0.8, 20, 8.6 and $8.0 \mathrm{ppb}$ respectively, using a $280 \mu \mathrm{m}$ spot size at $20 \mathrm{~Hz}$ repetition rate. Possible hydride formation was quantified on NIST 612 with ice present in the LA cell using three monitor masses at 233, 239 and 210 , i.e. ${ }^{232} \mathrm{ThH},{ }^{238} \mathrm{UH}$ and ${ }^{209} \mathrm{BiH}$, and resulted in hydride/element formation values $<0.5 \%$, with $\mathrm{ThO} / \mathrm{Th}$ at $\sim 0.2 \%$ and ${ }^{232} \mathrm{Th} /{ }^{238} \mathrm{U}>90 \%$.

As shown in Table 1, the following mass/charge ratios were acquired: 23(Na), 24(Mg), 27(Al), 34(S), 39(K), 40(Ca), 44(Ca), 55(Mn), 56( $\mathrm{Fe}), 65(\mathrm{Cu}), 85(\mathrm{Rb}), 88(\mathrm{Sr}), 89(\mathrm{Y})$, 138(Ba), 139(La), 140(Ce), 141(Pr), 147(Sm), 153(Eu), 157(Gd), 172(Yb), 208(Pb). Among these, only the following usually show resolvable signal/background ratio and will be displayed as results: 23(Na), 24(Mg), 27(Al), 40(Ca), 56(Fe), 88(Sr), 208(Pb). Mass 39(K), despite resolvable signal/background ratio, has a potentially significant contribution from ${ }^{38} \mathrm{ArH}$; therefore it will not be displayed in the results. Data acquisition was performed both as chains-of-spots and continuous tracks of different spot size. All the spot chains were carried out at $20 \mathrm{~Hz}$, with laser fluence of $\sim 3 \mathrm{~J} \mathrm{~cm}^{-2}$ for $40 \mathrm{~s}$ (800 pulses), plus $20 \mathrm{~s}$ of background. This produces a crater depth of $\sim 100 \mu \mathrm{m}$. Continuous tracks were acquired at $20 \mathrm{~Hz}$ repetition rate and $0.8 \mathrm{~mm} \mathrm{~min}^{-1}$ speed. To remove the surface contamination, each laser track was pre-ablated at $25 \mathrm{~Hz}$ at a speed of $3 \mathrm{~mm} \mathrm{~min}^{-1}$. 
Table 1. Operating conditions of cryo-cell UV laser ablation ICPMS RF power

Coolant gas flow

Auxiliary gas flow

Dwell time/mass Monitored masses $(\mathrm{m} / \mathrm{z})$

Sampler, skimmer cones

Extraction lenses

OctP bias

QP bias

QP focus

Hydride/element formation

${ }^{232} \mathrm{Th} /{ }^{238} \mathrm{U}$

ThO/Th $(248 / 232)$
ICPMS: Agilent 7500cS

Carrier gas flow
1190-1300 W (optimized daily) 650-700 $\mathrm{mL} \mathrm{min}^{-1}$ (optimized daily) $15 \mathrm{~L} \mathrm{~min}^{-1}$ $1 \mathrm{~L} \min ^{-1}$

$40 \mathrm{~ms}:{ }^{24} \mathrm{Mg},{ }^{27} \mathrm{Al},{ }^{40} \mathrm{Ca},{ }^{55} \mathrm{Mn},{ }^{56} \mathrm{Fe}$ $20 \mathrm{~ms}:{ }^{23} \mathrm{Na},{ }^{88} \mathrm{Sr}$ $15 \mathrm{~ms}:{ }^{85} \mathrm{Rb},{ }^{208} \mathrm{~Pb}$ $10 \mathrm{~ms}:{ }^{34} \mathrm{~S},{ }^{44} \mathrm{Ca},{ }^{89} \mathrm{Y},{ }^{138} \mathrm{Ba},{ }^{139} \mathrm{La}$, ${ }^{140} \mathrm{Ce},{ }^{141} \mathrm{Pr},{ }^{147} \mathrm{Sm},{ }^{153} \mathrm{Eu},{ }^{157} \mathrm{Gd},{ }^{172} \mathrm{Yb}$ $5 \mathrm{~ms}:{ }^{39} \mathrm{~K},{ }^{65} \mathrm{Cu}$

$\mathrm{H}_{2}(99.9999 \%), 4.5 \mathrm{~mL} \mathrm{~min}^{-1}$

$23,24,27,34,39,40,44,55,56,65$,

$85,88,89,138,139,140,141,147$, $153,157,172,208$

$\mathrm{Ni}$

Cs (tuning optimized for low masses) $-25 \mathrm{~V}$

$-20 \mathrm{~V}$

$-9 \mathrm{~V}$

$<0.5 \%$

$>90 \%$

$<0.5 \%$, typically $0.2 \%$

Laser-ablation system RESOlution M-50

Laser and wavelength

Energy density (fluence) on

target

He gas flow

$\mathrm{H}_{2}$ carrier gas flow addiction

Laser repetition rate

Laser spot size (circular)

Laser acquisition mode

Ar, $\mathrm{H}_{2}$ carrier gas

Signal smoothing

Cryo-cell sample holder

Cooling mechanism

Sample holder temperature

Holder material
193 nm excimer (CompexPro 110)

$3 \mathrm{~J} \mathrm{~cm}^{-2}$

850-900 $\mathrm{mL} \mathrm{min}^{-1}$ (optimized daily) 8-9 $\mathrm{mL} \mathrm{min}$ min $^{-1}$ (optimized daily) $20 \mathrm{~Hz}$

$128,164,280 \mathrm{~m}$

Chain-of-spots and tracks at 150, 200, $300 \mathrm{~m}$ spacing

Admixed downstream of LA cell 'Squid' included

Two Peltier elements

$-16^{\circ} \mathrm{C}$ (with $\mathrm{He}$ )

Anodized aluminium
Results are shown in net intensities, namely background corrected counts per second, so conversion into concentrations will not be displayed, similar to data from XRF core scanners (Weltje and Tjallingii, 2008). This is due to the lack of homogeneous $(<5 \%)$ external ice standard and due to the impossibility of finding an internal standard. Some external standards prepared at RHUL by building a volume of ice, adding frozen-shock layers of water with known concentration of elements, proved to be inhomogeneous (Müller and others, 2011). Internal standardization using ${ }^{17}(\mathrm{OH})$ is impossible because ICPMS background for mass 17 is too high. The feasibility of using mass $34\left({ }^{16} \mathrm{O}^{18} \mathrm{O}\right)$ as internal standard is currently under evaluation.

Elemental ratios are quantifiable assuming that ablation differences between NIST612 and particles in ice are insignificant. These ratios have been calculated according to Longerich and others (1996):

$$
\frac{C_{x}}{C_{y}}=\frac{I_{x_{-} \text {sample }}}{I_{y_{-} \text {sample }}} \frac{I_{y_{-} \text {std }}}{C_{y_{-} \text {std }}} \frac{C_{x_{-} \text {std }}}{I_{x_{-} \text {std }}}
$$

where $C_{x, y}$ are the concentrations of elements (ppm) in the sample or standard (NIST 612, from Jochum and others, $2011)$ and $I_{x, y}$ the net intensities (i.e. background-corrected) of elements $x$ and $y$ in the sample and the standard.
Instrumental drift was monitored by analysing NIST 612 at regularly spaced intervals and corrected daily, linearly normalizing the intensity according to

$$
I_{\text {sensitivity normalized }}=I_{\text {measured }} \cdot f_{\mathrm{N}}
$$

$f_{\mathrm{N}}$ is the normalizing factor and is equal to $\frac{l_{\text {average per ppm }}}{I_{\text {measured per ppm }}}$. $l_{\text {average per ppm }}$ is the ratio between intensity of element $x$ and concentration of element $x$ averaged over all the ablations of NIST612 during one acquisition campaign, and $I_{\text {measured per ppm }}$ is the ratio between intensity of element $x$ and concentration of element $x$ of the NIST612 acquisition closest to the sample acquisition.

Intensities of isotopes acquired as one-dimensional (1-D) profiles and two-dimensional (2-D) maps were recalculated as elemental intensities based on their relative isotopic abundance taken from Henderson and Henderson (2009). Images of the surface of the samples were obtained with the viewing system of the laser after the surface was smoothed with the $\mathrm{ZrO}_{2}$ blade, and show boundaries of mm-sized grains in fine detail, allowing deliberate acquisition of data along profiles that cross grain boundaries and triple junctions. The drilling of a single spot (Fig. 3a) shows a transient peak 10-20 times higher than the actual signal, interpreted as surface contamination and followed by a gentle decrease typical of spot drilling. During data reduction, a baseline was fitted interpolating the background intervals between spot acquisitions. The baseline was subtracted from the signal, and surface contamination removed by cutting out the first $10 \mathrm{~s}$ of every spot acquisition. A regression line was then fitted to the remaining net signal $(30 \mathrm{~s})$, and the $y$-intercept at $t=0$ of every line was assumed as the value representative of each spot drilled, allowing error calculation as $\pm 2 \sigma$. The values were then corrected for instrumental drift according to Eqn (7), and the intensity maps of analytes were interpolated from the values obtained in this manner. Due to the relatively high $\mathrm{Na}$ background (Fig. $3 \mathrm{a}$ ), the $\mathrm{Na}$ signal was carefully hand-picked from sections where it was resolvable.

\section{RESULTS}

Data were acquired both as 1-D profiles and 2-D maps on five $50 \mathrm{~mm}$ ice strips, which were carefully surface-cleaned in order to avoid contamination by using the custom-built PTFE vice equipped with a $\mathrm{ZrO}_{2}$ blade. Results are displayed in Figures 5-19 and Table 2.

A total of 251 -D profiles were acquired over areas of clear ice, and another 25 were acquired on adjacent cloudy bands in the five samples analysed. Of these 50 profiles a representative selection of 22 is shown in results. Cloudy bands form when the transport and deposition of impurities increase due to seasonal events such as atmospheric storms (Svensson and others, 2005). The more particles are present, the more the layers will appear bright in the scan images due to light scattering. For the same reasons, clear ice appears dark because it does not contain high amounts of impurities. The profiles were acquired both as chains-of-spots and tracks of $128 \mu \mathrm{m}$ size over cloudy bands and of 164 or $280 \mu \mathrm{m}$ size over clear ice. Cloudy bands and clear ice were identified in the ice sample combining scan images of the core for the selected interval taken by Svensson and others (2005) with images acquired in transmitted and reflected light with the laser camera, which show a fairly good 


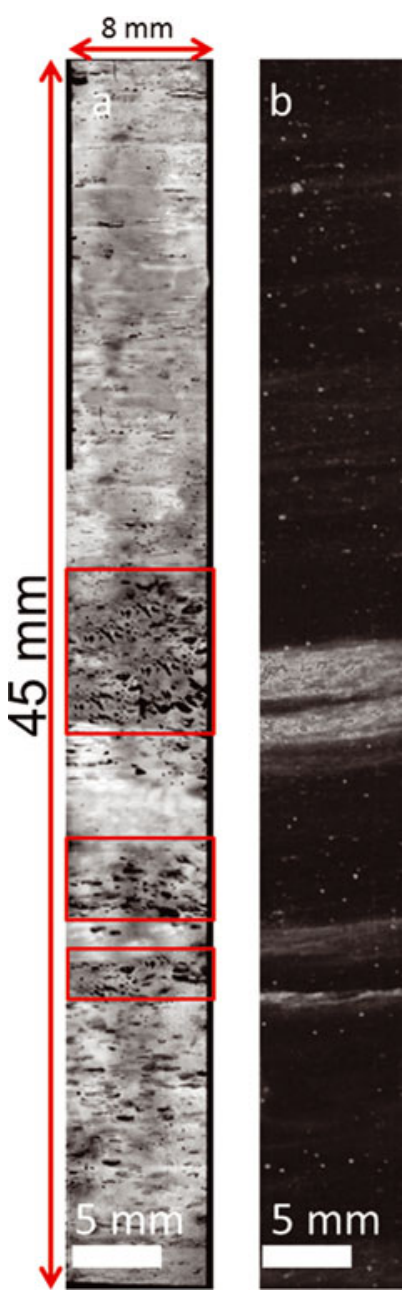

Fig. 4. (a) Transmitted-light image of an entire NGRIP subsample (4882_B5) taken with the camera of the laser ablation system. Cloudy bands are highlighted in the red boxes. (b) Corresponding zoom-in of the scanned image of the sample (Svensson and others, 2005) showing similar variation of cloudy bands and clear ice. The discrepancy is attributable to the parallax error that exists between the two surfaces shown in (a) and (b), which are parallel but a few $\mathrm{cm}$ apart (Fig. 1c).

correspondence (Fig. 4). The profiles shown were deliberately acquired both across and along grain boundaries (Figs 5-15). On average, in clear ice the intensities span five to six orders of magnitude and the variability of each element ranges over two orders of magnitude. Ca is usually the highest analyte, followed by $\mathrm{Na}, \mathrm{Al}, \mathrm{Fe}, \mathrm{Mg}, \mathrm{Sr}$ and $\mathrm{Pb}$. Owing to the elevated level of impurities, the smaller spot size utilized for cloudy bands allows them to be analysed at higher spatial resolution. Intensities of elements, despite the smaller spot size resulting in an approximately fivefold signal drop between 280 and $128 \mu \mathrm{m}$, are comparable with those acquired for clear ice. For most elements the cloudyband data show continuous profiles with no significant peaks corresponding clearly to grain boundaries. On the other hand, in clear ice, most of the intensity peaks are visibly related to ablation over grain boundaries. In the five samples analysed, this pattern is undoubtedly identified in 17 of the 25 profiles acquired on clear ice. The other eight do not present such an unequivocal correlation between grain boundaries and intensity. In the case of cloudy bands, 20 of the 25 profiles show no increase in intensities of elements along boundaries, while the other 5 reveal slight increases of intensities of one or more elements. In the 50 profiles analysed, the average grain-size differences between cloudy bands and clear ice are not very large but amount to $\sim 20 \%$, with grains measuring on average 2.5 and $3.2 \mathrm{~mm}$ respectively (at the longest axis of the grains). All the images of ice surfaces shown in Figures 5-19 were obtained with the camera attached to the viewing system of the laserablation system in either reflective or transmitted light illumination, to better highlight grain boundaries. Black dashed lines were drawn along the grain boundaries wherever they were not evident. Figures 5-9 show compositional data of both chains-of-spots and tracks of regular and irregular shape, in many cases parallel to each other, acquired on identified cloudy bands, deliberately intercepting several grain boundaries at various angles.

The elemental intensities in cloudy bands are overall relatively flat, with no significant oscillations (Figs 6 and 9), or present some intra-profile variability (Figs 5, 7 and 8), but all the local peaks in such profiles correspond to locations in the interior of grains and not to grain boundaries. The interelemental variability in cloudy bands is not pronounced, with the exception of a few Fe and $\mathrm{Al}$ peaks (Fig. 6b spot No. 9; Fig. 7a spot No. 6). An interesting example is shown in Figure 7a, spot No. 6, where ablation across a boundary corresponds to a decrease in intensity of one order of magnitude for all the elements except Fe, which by contrast increases by two orders of magnitude. This might be due to the presence of an iron-rich particle that was situated on the boundary.

In clear ice, the compositional profiles show peaks where the highest intensities clearly correspond to boundaries and triple junctions (Figs 10-15). In most cases, the intensity of the peaks exceeds one order of magnitude relative to the adjacent spots. Interestingly, a junction area where four grains are connected corresponds to a much broader peak compared to simple grain contacts, and thus likely corresponds to a larger area of enriched impurities (Fig. 10b, spots 12-14). The intra-element variability in clear ice is greater compared to cloudy bands, but inter-elemental differentiation is negligible. However, also in this case, a few minor exceptions are present (Fig. 10b, spot No. 9; Fig. 12a, spot No. 14), and some elements show different trends or amplitude of increase/decrease between each other.

Table 2. Comparison between $\mathrm{Ca} / \mathrm{Al}$ and Fe/Al ratios from different sources of dust (modified from Lee and others, 2010). The values obtained in this work show affinity with a mix of dust from east Asian deserts such as the Taklamakan and Gobi

\begin{tabular}{lcccccc}
\hline & Non-East Asian & Gobi & Taklamakan & Upper crust & China loess & Present study \\
\hline $\mathrm{Ca} / \mathrm{Al}$ & 1.5 & 1.6 & 2.6 & $0.37-0.47$ & 1.08 & $2.1 \pm 0.4(2 \mathrm{~s} . \mathrm{e})$. \\
$\mathrm{Fe} / \mathrm{Al}$ & 0.7 & 1.3 & 2 & $0.42-0.57$ & 0.5 & $1.5 \pm 0.3(2 \mathrm{~s} . \mathrm{e})$. \\
\hline
\end{tabular}



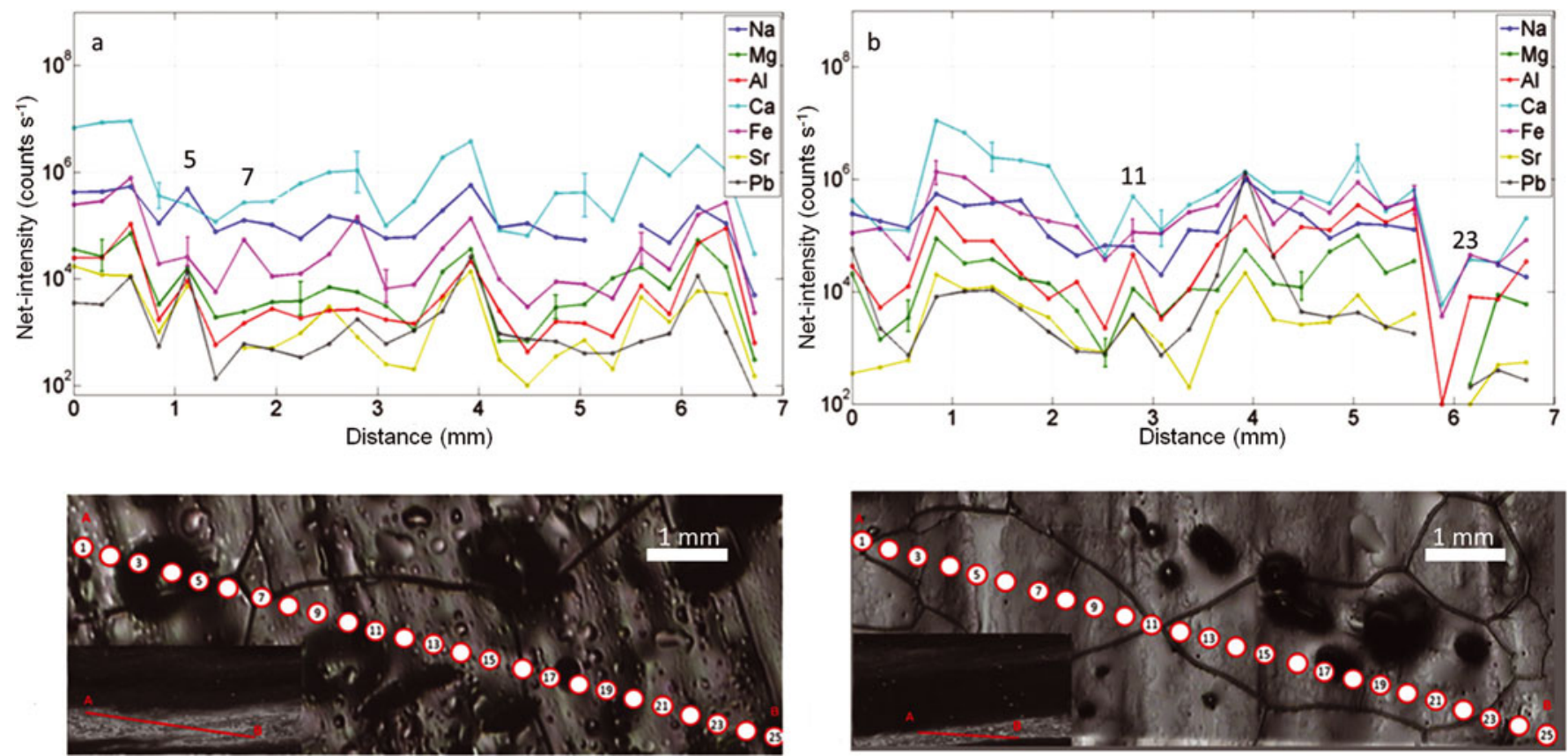

Fig. 5. (a, b) Cloudy band areas of NGRIP sample 4900_A5 (2694.75-2694.8 m). Chain of 25 spots with diameter of $128 \mu \mathrm{m}$ at $150 \mu \mathrm{m}$ spacing along two profiles of $\sim 6.5 \mathrm{~mm}$ from A to B (see insets in the bottom left). No correlation between intensities and grain boundaries is observed for cloudy bands. Representative $2 \sigma$ error bars are shown for $\mathrm{Na}, \mathrm{Mg}$ and $\mathrm{Ca}$.

A comparison between profiles acquired along grain boundaries in cloudy bands and clear ice is shown in Figure 15. In the first case (Fig. 15a), the elemental intensities are similar to those of the rest of the profiles acquired in cloudy bands. In contrast, in clear ice the data are up to one order of magnitude higher than average values (note the $y$-axis scale up to $10^{10}$ ), with local peaks that correspond to triple junctions.

Compositional data of $\mathrm{Na}, \mathrm{Mg}, \mathrm{Al}, \mathrm{Ca}$ and Fe from a 2-D grid of spots $(9 \times 35$ spots with $280 \mu \mathrm{m}$ diameter $)$ over a $27 \times 6 \mathrm{~mm}$ surface of ice from NGRIP at $\sim 2695 \mathrm{~m}$ depth (sample 4899_A7) are shown in Figure 16. Sr and Pb could
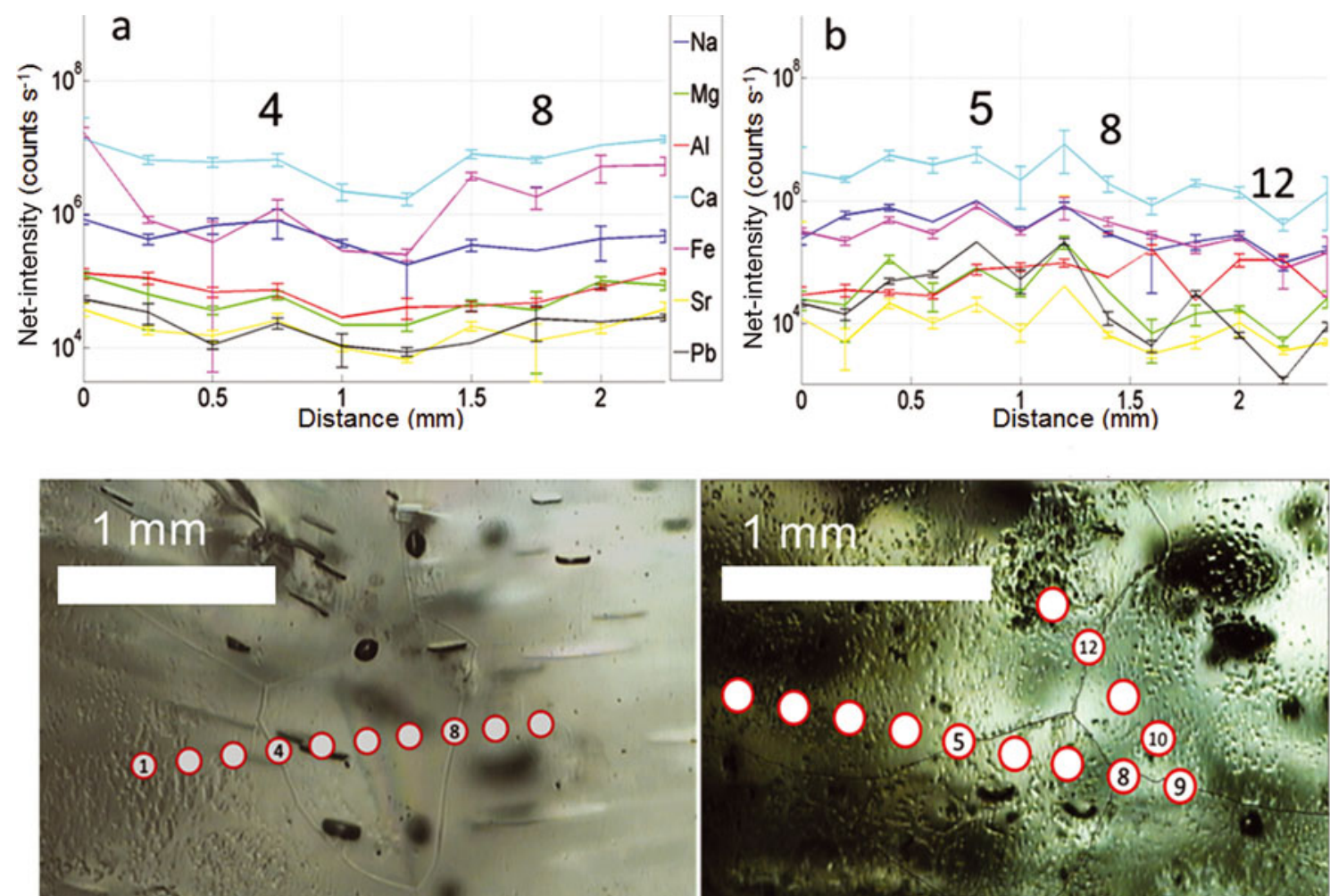

Fig. 6. (a, b) Profiles acquired in cloudy band areas of NGRIP sample 4946_B4 (2720.075-2720.125 m). Chain of 10 and 13 spots respectively, diameter $128 \mu \mathrm{m}$, spacing $150 \mu \mathrm{m} ; 2 \sigma$ error bars are shown. No correlation between intensities and grain boundaries is observed. 
$a$
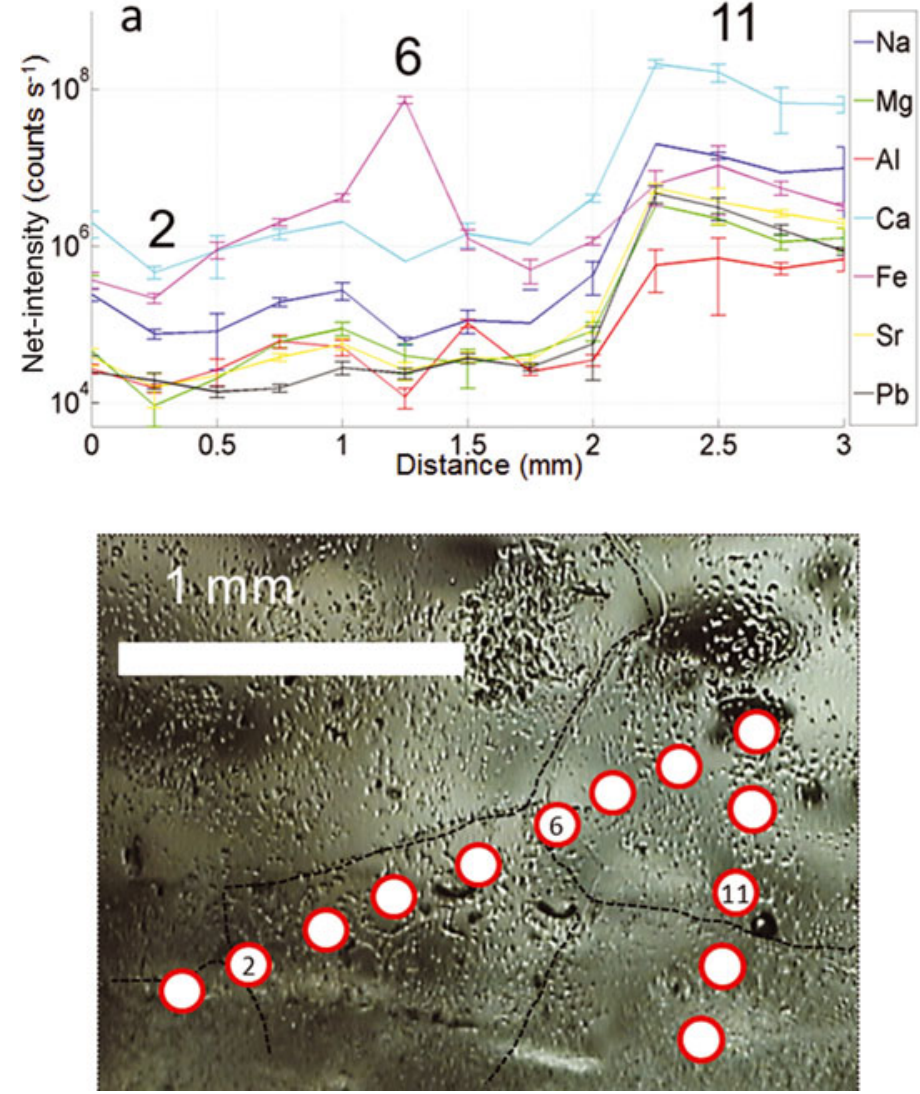

b

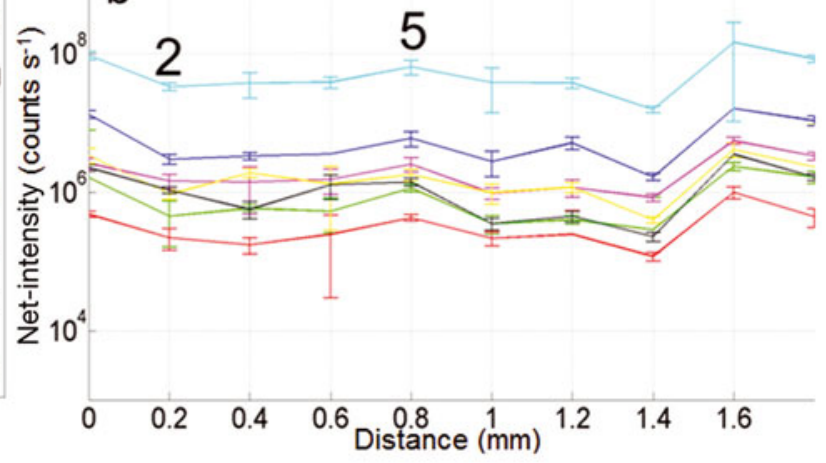

Fig. 7. (a, b) Profiles acquired in cloudy band areas of NGRIP sample 4882 B5 (2684.825-2684.875 m). Chain of 13 and 10 spots respectively, diameter $128 \mu \mathrm{m}$, spacing $150 \mu \mathrm{m} ; 2 \sigma$ error bars are shown. No correlation between intensities and grain boundaries is observed. Spot No. 6 in (a) shows a Fe peak which could be a contribution from ablation of an iron-rich particle.

not be sufficiently resolved in this case. The maps show a strong small-scale variability (up to $10^{5}$ counts s$^{-1}$ in $1 \mathrm{~mm}$ ), higher intensities within cloudy bands, and a general patchy behaviour where areas of extreme values tend to occur within grain interiors rather than near boundaries. The highest-intensity elements are again $\mathrm{Ca}$ and $\mathrm{Al}$ followed by $\mathrm{Fe}, \mathrm{Na}$ and $\mathrm{Mg}$. From the bottom to the top of every map we can distinguish two alternations of bands of low/high intensities whose inclination varies from $30^{\circ}$ to $60^{\circ}$ from the horizontal axis, dipping to the right, plus another band of low intensities on the top. This alternation is best visible for $\mathrm{Na}$ and $\mathrm{Fe}$, but is less clear for $\mathrm{Ca}, \mathrm{Al}$ and $\mathrm{Mg}$. The scan image shown in Figure 16b again presents two alternations of bright layers and clear ice which broadly appear to correlate to the intensity bands, although the lower bright layers in Figure $16 \mathrm{~b}$ are not well defined. A direct correlation is also made difficult by the fact that the surface scanned for visual stratigraphy (Svensson and others 2005) and the surface analysed by UV-LA-ICPMS are not the same. In fact, as shown in Figure 1c, the sample surface and the scanned surface are few $\mathrm{cm}$ apart, although they represent exactly the same depth. As the layers are wavy at this depth, small variations between the two surfaces are to be expected (parallax effect). However, the most intense zone of the elemental maps of $\mathrm{Na}$, Fe and partially $\mathrm{Al}, \mathrm{Ca}$ and $\mathrm{Mg}$ match the brightest cloudy bands in Figure $16 \mathrm{~b}$ (tilted by $\sim 25^{\circ}$ ). The different elements show their highest intensities in various areas of the map, with $\mathrm{Ca}, \mathrm{Al}$ and $\mathrm{Mg}$, yet contrasting peaks from the top to the bottom of the map. These peaks are generally not related to grain boundaries. Figure 16a shows that the grain sizes range between $<1 \mathrm{~mm}$ (at the top and bottom of the section) and several millimetres (middle part of the section).

A second $2-D$ grid of $27 \times 13$ spots $(164 \mu \mathrm{m}$ spot size, $200 \mu \mathrm{m}$ spacing) from an undeformed cloudy band was mapped for $\mathrm{Na}, \mathrm{Mg}, \mathrm{Al}, \mathrm{Ca}, \mathrm{Fe}, \mathrm{Sr}$ and $\mathrm{Pb}$ (Figs 17-19) from a depth of 2694.75-2694.8 m (sample 4900_A5). Overall, Ca shows the highest intensities, followed by, Fe and Al and in turn by $\mathrm{Na}$ and $\mathrm{Mg}$. $\mathrm{Sr}$ and $\mathrm{Pb}$ have intensities at least two orders of magnitude smaller than the other elements. All the maps confirm the tendency of elements to concentrate in patches with an internal variability that covers six orders of magnitude for $\mathrm{Al}, \mathrm{Ca}$ and $\mathrm{Fe}$ and from five to three orders for the others. All the elements seem to have similar distributions, having higher intensities in the top part, and lower in the bottom part, with differences in some cases (cf. symmetric behaviour of $\mathrm{Al}$ and Fe compared to $\mathrm{Ca}$ in the top part). The image obtained with the laser camera (Fig. 17) shows a noticeable variation of grain size, going from $\mathrm{mm}$ sized grains in the bottom left part of the map to hundredsof-micron-sized grains in the right middle part of the map. $\mathrm{Mg}$ intensities are relatively homogeneous throughout the section, with maxima at the top and minima at the bottom. The same behaviour is presented by $\mathrm{Ca}$ and $\mathrm{Sr}$, despite the upper section of the map showing decreasing intensities from left to right. A different pattern is presented by $\mathrm{Al}$ and $\mathrm{Fe}$, where the variability between the upper and the lower part of the map is more accentuated and the upper part of the section shows decreasing intensities from right to left, opposite to $\mathrm{Ca}$. Na has generally low intensities except in the uppermost part of the map, where it creates a sub-mm layer of high intensities that contrasts remarkably with the 

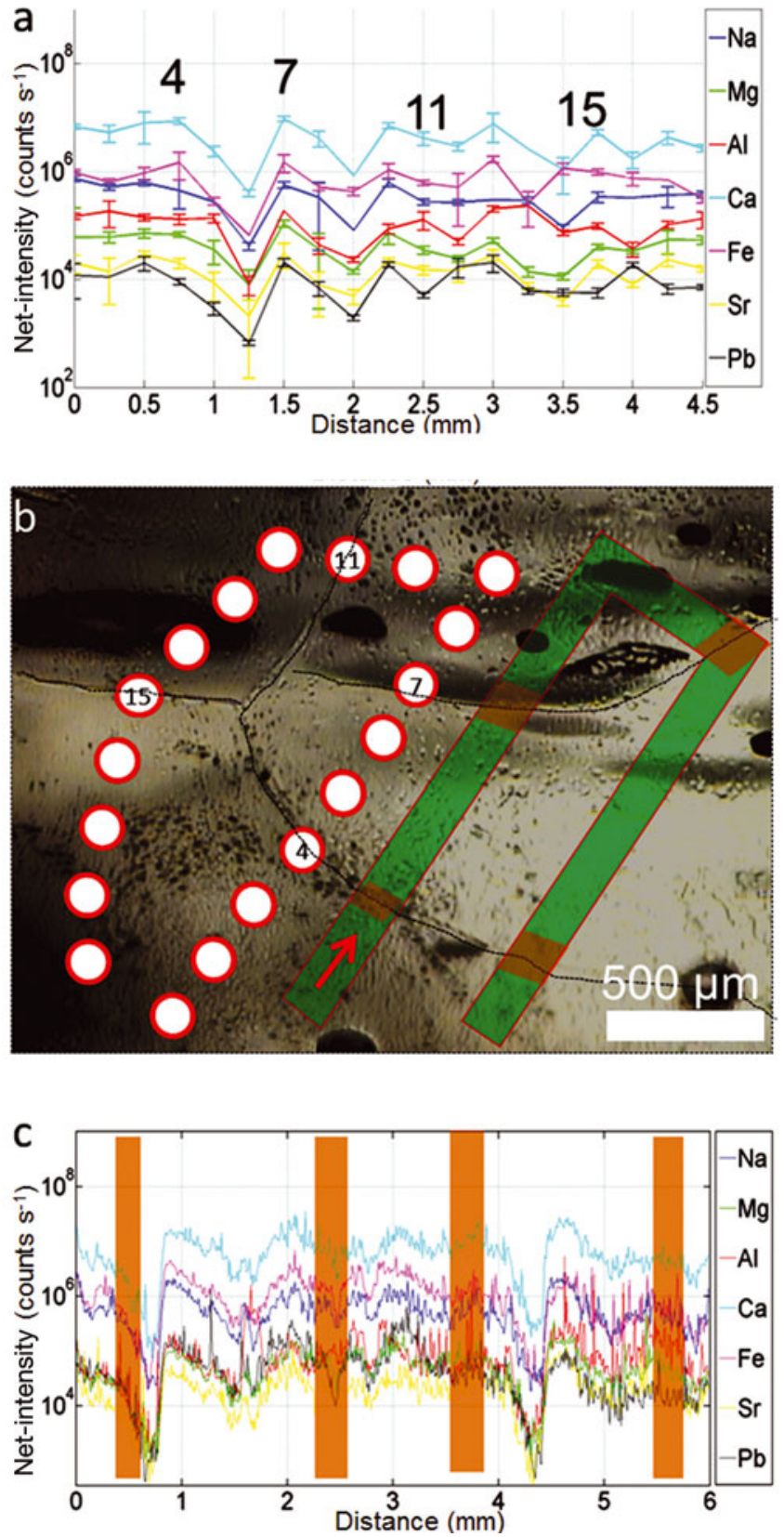

Fig. 8. Comparative, parallel profiles across several ice grains acquired both as chain-of-spots and continuous track - in a cloudy band of NGRIP sample 4899_B8 (2694.025-2694.075 m). (a) Netintensities of selected elements along a chain of 19 spots $(128 \mu \mathrm{m}$ diameter, $150 \mu \mathrm{m}$ spacing) with $2 \sigma$ error bars. Grain boundaries are marked by spot numbers. (b) Image of the surface of the ice sample, with indications of the chain-of-spots and track visible in (a) and (c). The red arrow indicates start and direction of the track. (c) Netintensities of selected elements along the continuous track alongside the chain-of-spots in (a) (pre-cleaning with $164 \mu \mathrm{m}, 25 \mathrm{~Hz}$, $50 \mu \mathrm{m} \mathrm{s}^{-1}$; acquisition with $128 \mu \mathrm{m}, 20 \mathrm{~Hz}, 13.3 \mu \mathrm{m} \mathrm{s}^{-1}$ ), where grain boundaries are indicated by shading. No correlation between intensities and grain boundaries is observed.

rest of the map but perfectly matches a layer of clearer ice, visible in the scan image (Fig. 18a). Sr shows similarities with the maps of $\mathrm{Ca}$ and $\mathrm{Mg}$, but its intensities are at least two orders of magnitude lower and fairly homogeneously distributed throughout the map. $\mathrm{Pb}$, in contrast, has a stronger internal variability and even lower intensities. Elemental maps show a variability of intensities which cannot be ascribed to grain boundaries, since, for most of
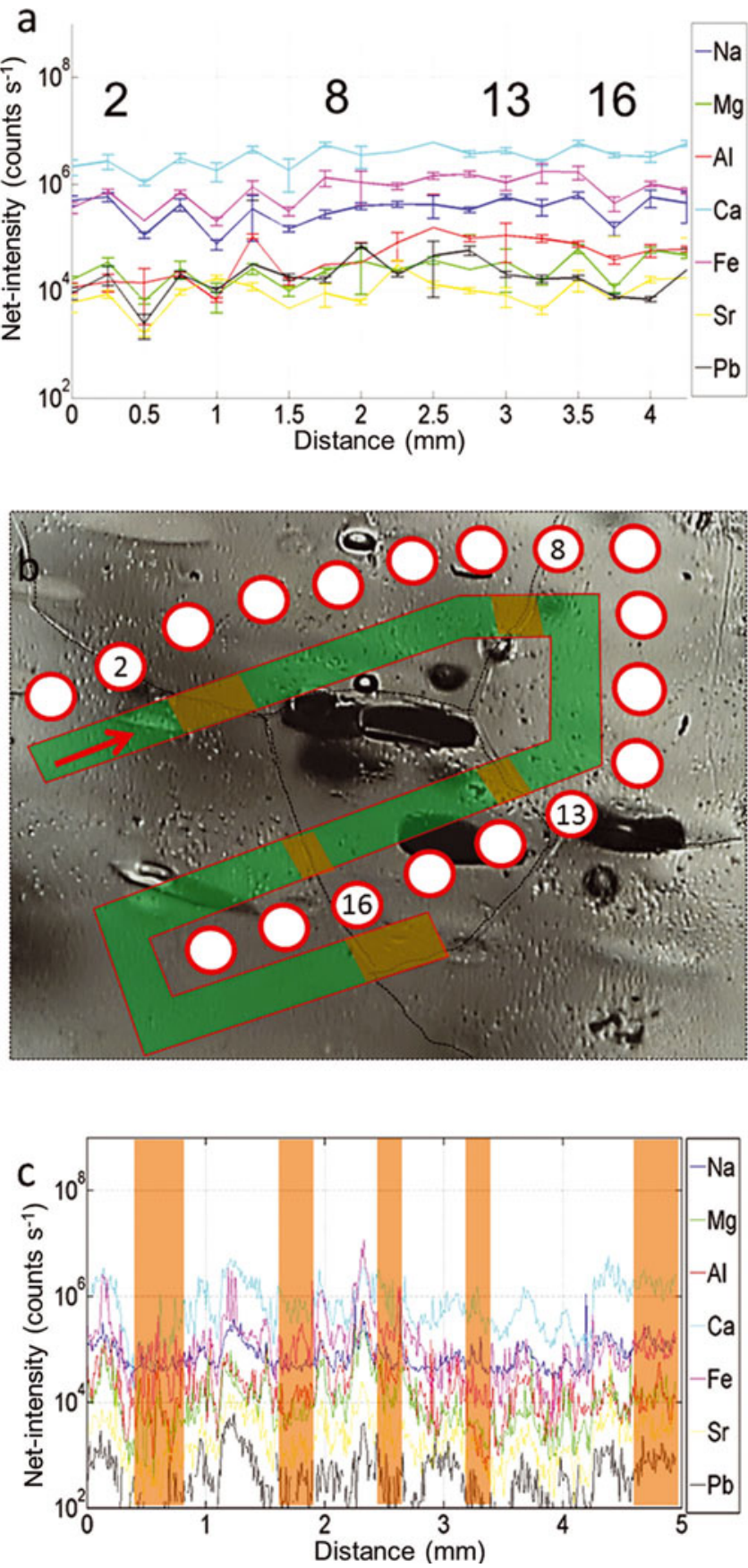

Fig. 9. Same as Figure 8, but for NGRIP sample 4946_B4 (2720.075-2720.125 m) and with 18 spots.

the elements, highest and lowest peaks appear within the grain interiors.

In order to compare results from this cloudy band with various crustal sources, $\mathrm{Ca} / \mathrm{Al}$ and $\mathrm{Fe} / \mathrm{Al}$ ratios were calculated (quantified relative to NIST612) and are shown in Figure $19 \mathrm{c}$ and $\mathrm{d}$. The maps have values that range between 0 and 14 , and overall values of $2.1 \pm 0.4(2 \times$ standard error $)$ (2s.e.) and $1.5 \pm 0.3$ (2s.e.) respectively. The bottom half of each map is very similar, whereas the upper half shows different patterns when comparing $\mathrm{Ca} / \mathrm{Al}$ and $\mathrm{Fe} / \mathrm{Al}$. In fact, zones of high $\mathrm{Ca} / \mathrm{Al}$ values almost perfectly match those with low $\mathrm{Fe} / \mathrm{Al}$ ratios and vice versa. The average values of both $\mathrm{Ca} / \mathrm{Al}$ and $\mathrm{Fe} / \mathrm{Al}$ ratios of the sections compare well with values from Asian deserts (Table 2), which are known to be the predominant source of Greenland dust during the last glacial period (Svensson and others, 2000). 

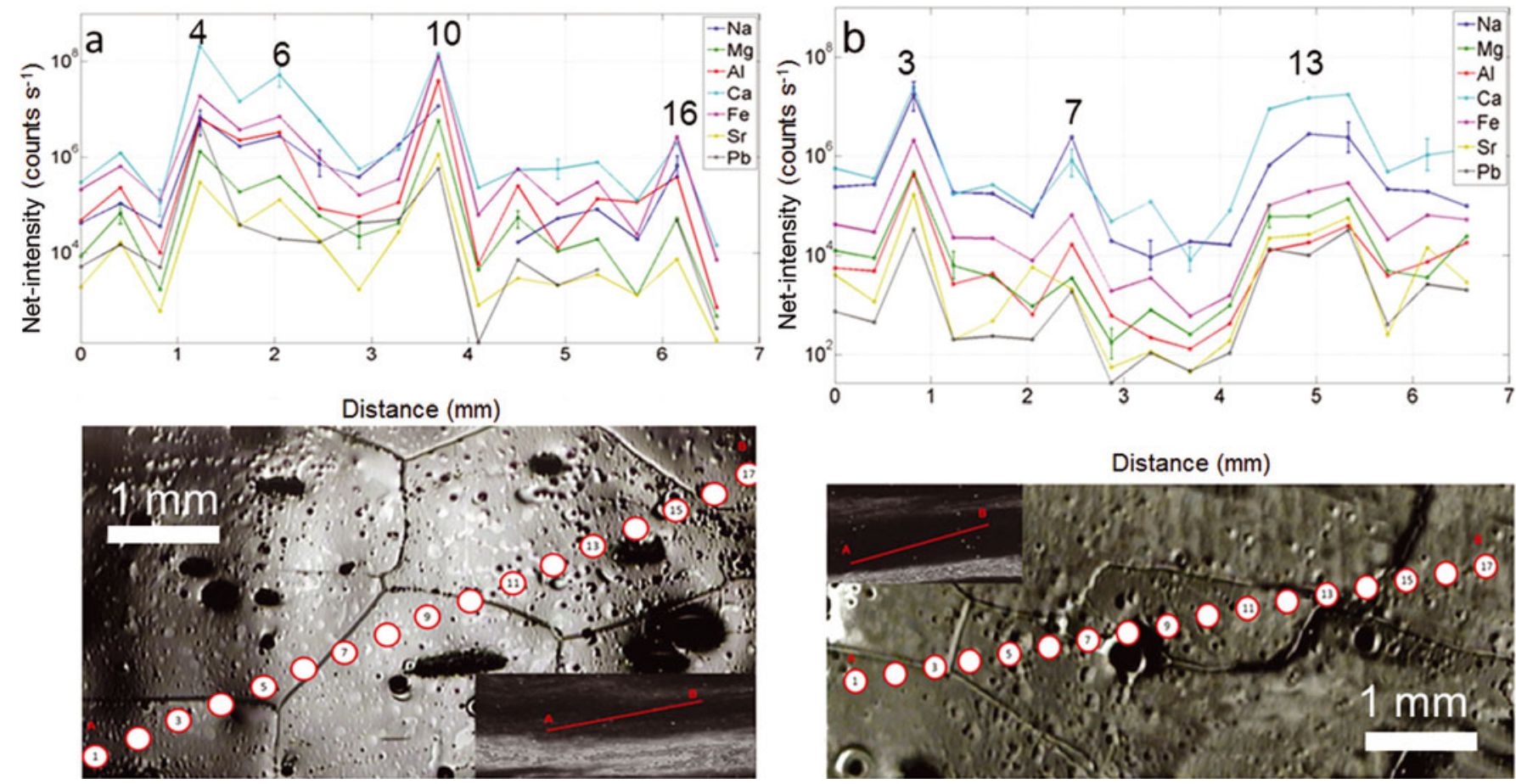

Fig. 10. (a, b) Profiles acquired over clear ice on NGRIP sample 4900_A5 (2694.75-2694.8 m). Two chains of 17 spots with diameter of $280 \mu \mathrm{m}$ at $300 \mu \mathrm{m}$ spacing were acquired along the profiles of $\sim 6.5 \mathrm{~mm}$ from A to B (see insets in the bottom right and upper left corner respectively). A strong correlation between intensities and grain boundaries is observed. Representative $2 \sigma$ error bars are shown for elements $\mathrm{Mg}, \mathrm{Ca}$ and Fe.
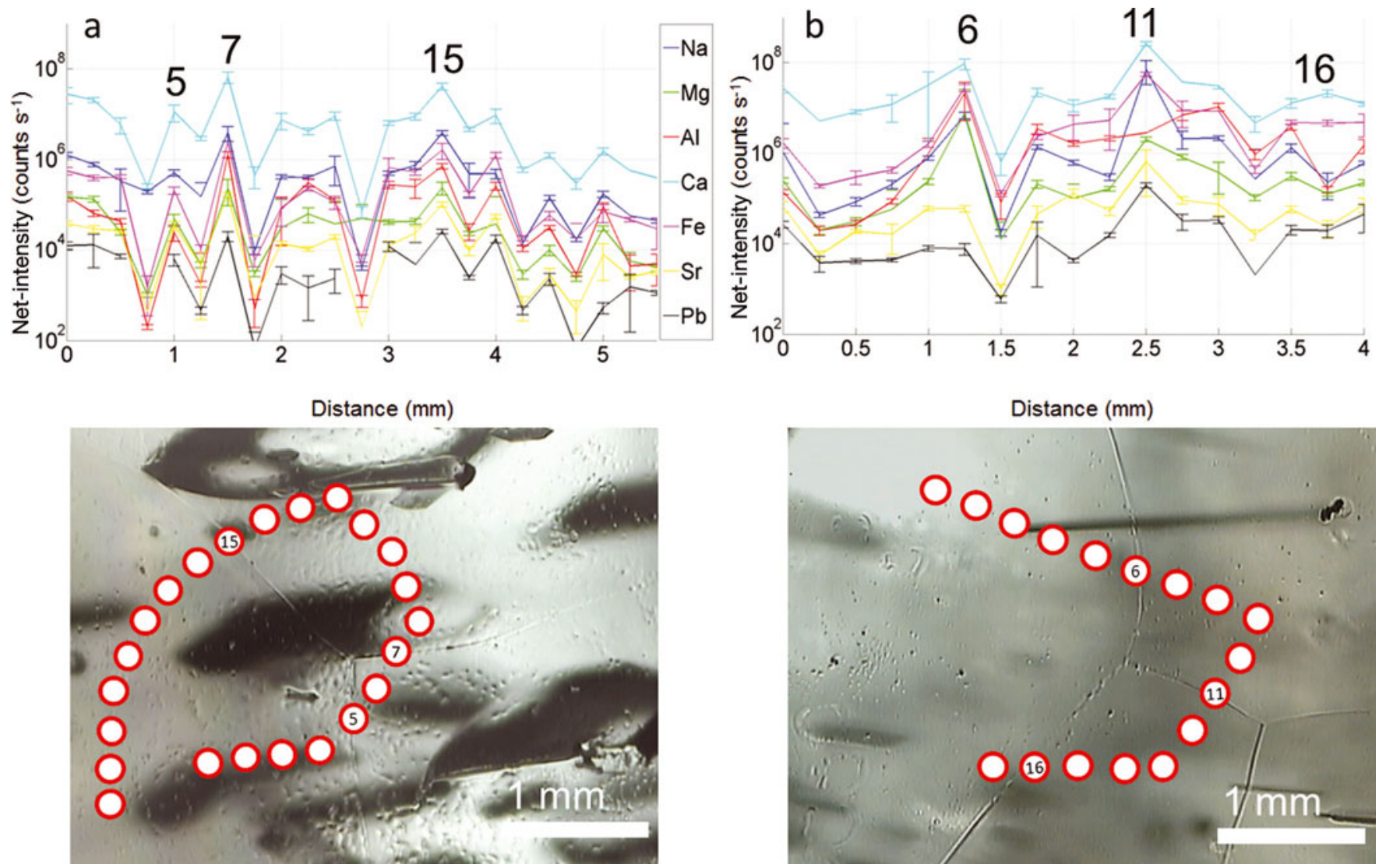

Fig. 11. (a, b) Profiles acquired in clear ice areas of NGRIP sample 4946_B4 (2720.075-2720.125 m). Chain of 23 and 17 spots respectively, diameter $164 \mu \mathrm{m}$, spacing $200 \mu \mathrm{m}$; $2 \sigma$ error bars are shown. Good correlation between intensities and grain boundaries is observed. 

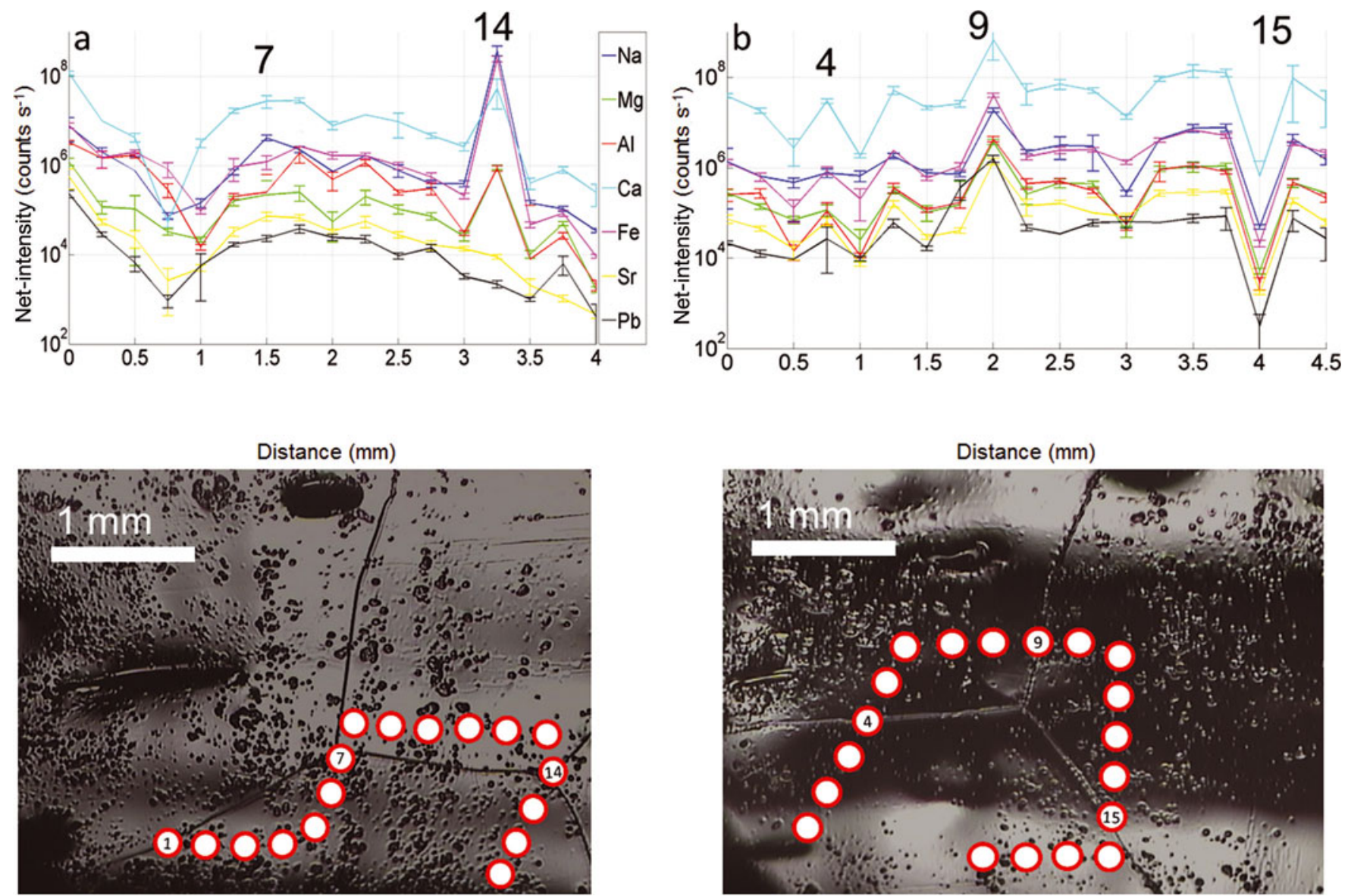

Fig. 12. (a, b) Profiles acquired in clear ice areas of NGRIP sample 4882_B5 (2684.825-2684.875 m). Chain of 17 and 19 spots respectively, diameter $164 \mu \mathrm{m}$, spacing $200 \mu \mathrm{m} ; 2 \sigma$ error bars are shown. Good correlation between intensities and grain boundaries is observed.

\section{DISCUSSION}

Visual comparison between scanned images from NGRIP (Svensson and others, 2005) and other ice-core records shows that NGRIP is rather well preserved, the integrity of the original horizontal layering being preserved down to $>2750 \mathrm{~m}$ depth. Millimetre-scale folds are observed only from a depth of $\sim 2700 \mathrm{~m}$ downwards (Fig. 1) with tilting of the layers (Fig. 16b) up to $30^{\circ}$. Nevertheless, the layering is always resolvable and preserved and no folding is observed in the samples investigated herein. Smoothing of the ice surfaces with a ceramic $\mathrm{ZrO}_{2}$ blade, mounted on a custombuilt PTFE vice, makes the grain boundaries easily identifiable with the viewing system of the laser ablation system, and also removes sample contamination from cutting.

Deep UV laser ablation of ice is a controlled process and yields smooth intensities over the duration of an analysis. Moreover, it generates circular craters both in the middle of ice grains (Fig. 3b) and along boundaries as well as triple junctions (Fig. 3c). Analyte background/signal ratios proved to be resolvable using spot sizes of 280, 212, 164 and $128 \mu \mathrm{m}$, achieving the best compromise between high spatial resolutions for spot sizes of 164 or $128 \mu \mathrm{m}$ at $20 \mathrm{~Hz}$ repetition rates.

The profiles acquired over cloudy bands (Figs 5-9) and over clear ice (Figs 10-14) show that the former are characterized by approximately fivefold increases in elemental intensities compared to the latter, which is consistent with cloudy bands being layers enriched in impurities (Svensson and others, 2005). This also matches with visual comparisons between clear ice and cloudy bands on scan images. The profiles for clear ice reveal that significantly higher elemental concentrations occur at grain boundaries or triple junctions, relative to the inner parts of the grains, which in many cases are slightly larger than in cloudy bands. However, in cloudy bands all the elements show generally similar patterns, though sometimes a few elements (especially Fe and $\mathrm{Al}$ ) have significant anticorrelation that might be related to horizontal or vertical variations of the composition and concentration of the impurities. In clear ice, $\mathrm{Na}$ has a much stronger variability and intensity, sometimes even higher than that of $\mathrm{Ca}$, whereas in cloudy bands the variability decreases. This reflects the seasonality peak of $\mathrm{Na}$ that appears in winter, which usually corresponds to clear ice. As a sea-salt proxy, Mg shows lower intensities in clear ice compared to cloudy bands, opposite to $\mathrm{Na}$. Contribution to $\mathrm{Mg}$ abundance from dust in such cases is probably larger than the sea-salt peak contribution, which marks the difference between clear ice (winter) and cloudy bands (spring).

The profiles over cloudy bands were taken from the layers immediately below the clear ice sections analysed. In these cases, no clear relationships between the intensities observed and grain boundaries are noticed. The observed compositional variability is not related to differences due to preferential distribution of impurities between boundaries and grains, since both the highest peaks and the lowest dips are found within the ice grains. Compared to clear ice, intensities of elements on boundaries are generally lower, 

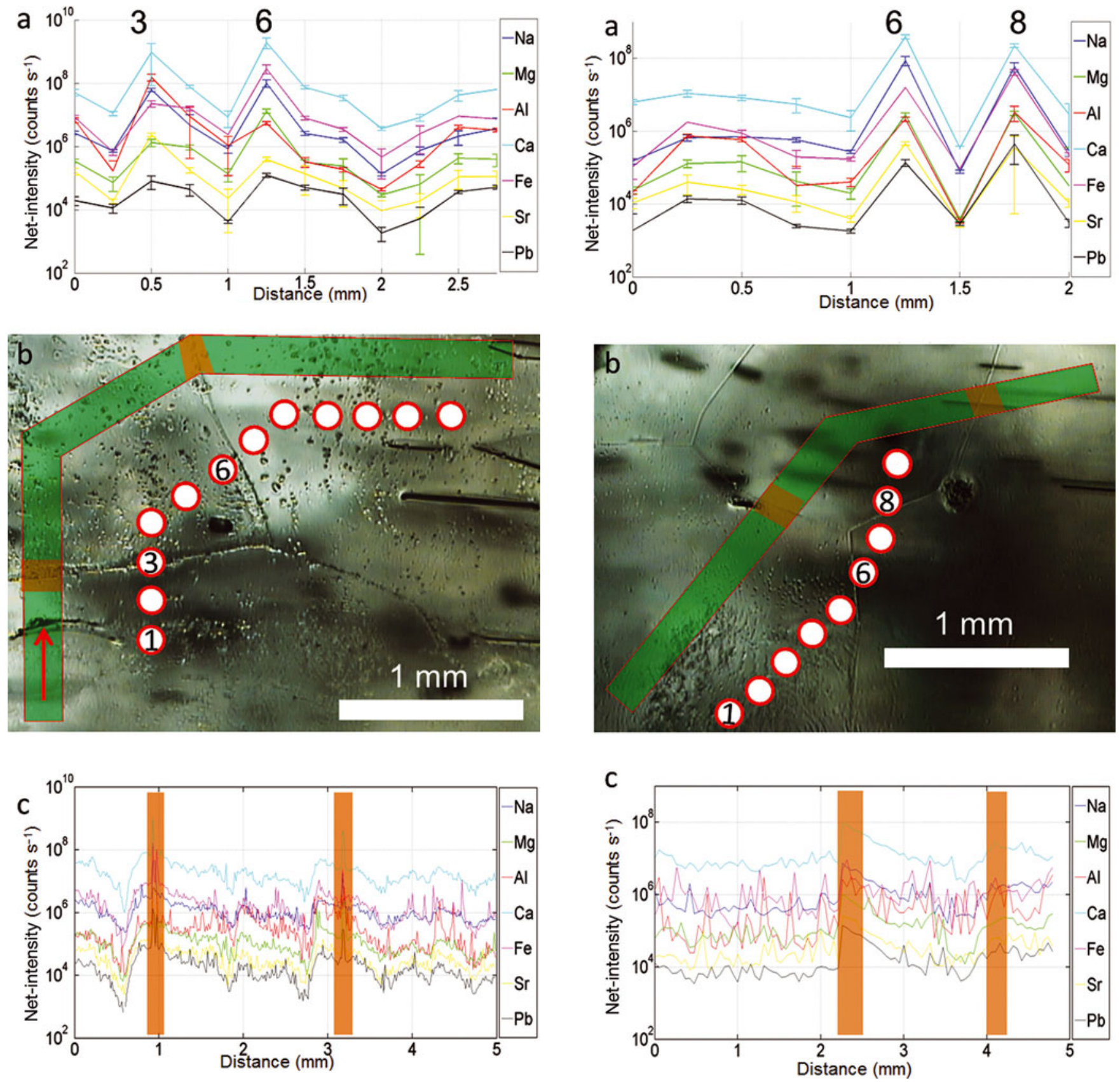

Fig. 13. Comparative, parallel profiles across several ice grains acquired both as chain-of-spots and continuous track - in a cloudy band of NGRIP sample 4899_A7 (2694.1-2694.15 m). (a) Netintensities of selected elements along a chain of 12 spots $(164 \mu \mathrm{m}$ diameter, $200 \mu \mathrm{m}$ spacing) with error bars $(2 \sigma)$. Grain boundaries are marked by spot numbers. (b) Image of the surface of the ice sample, with indications of the chain-of-spots and track visible in (a) and (c). The red arrow indicates start and direction of the track. (c) Net intensities of selected elements along the continuous track alongside the chain-of-spots in (a) (pre-cleaning with $196 \mu \mathrm{m}$, $25 \mathrm{~Hz}, 50 \mu \mathrm{m} \mathrm{s}^{-1}$; acquisition with $164 \mu \mathrm{m}, 20 \mathrm{~Hz}, 13.3 \mu \mathrm{m} \mathrm{s}^{-1}$ ), where grain boundaries are indicated by shading. A good correlation between intensities and grain boundaries is observed.

and this pattern is almost identical for every element. In some cases (Fig. 7a, spot No. 6), a dip in intensity of one order of magnitude for all the elements corresponds to a rise in intensity of Fe of two orders of magnitude. This effect shows the possibility of having microparticles of different nature on a very fine scale, which may be located on both boundaries and grain interiors.

Fig. 14. Same as Figure 13, but for NGRIP sample 4882_B5 (2684.825-2684.875 m) and with nine spots.

Elemental maps reveal sub-mm variability of concentrations, having maxima in correspondence to cloudy bands (Fig. 16), although elemental concentration does not exactly match the distribution of impurities inferred from the scan images, not least because the two surfaces do not exactly correspond, as images were taken from the centre whereas the analysed samples are from outer core ice. The overall distribution of impurities is not confined to grain boundaries, suggesting that it is not influenced by eventual grain boundary migration.

The $27 \mathrm{~mm}$ section represented in Figure 16 seems to be compatible with a 2 year cycle, given the layer thickness at this depth for the NGRIP core $(\sim 12 \mathrm{~mm})$. The cycle is well represented in all elemental maps, having two alternations of low/high concentration from the bottom upwards, plus another low-concentration zone at the very top, although 

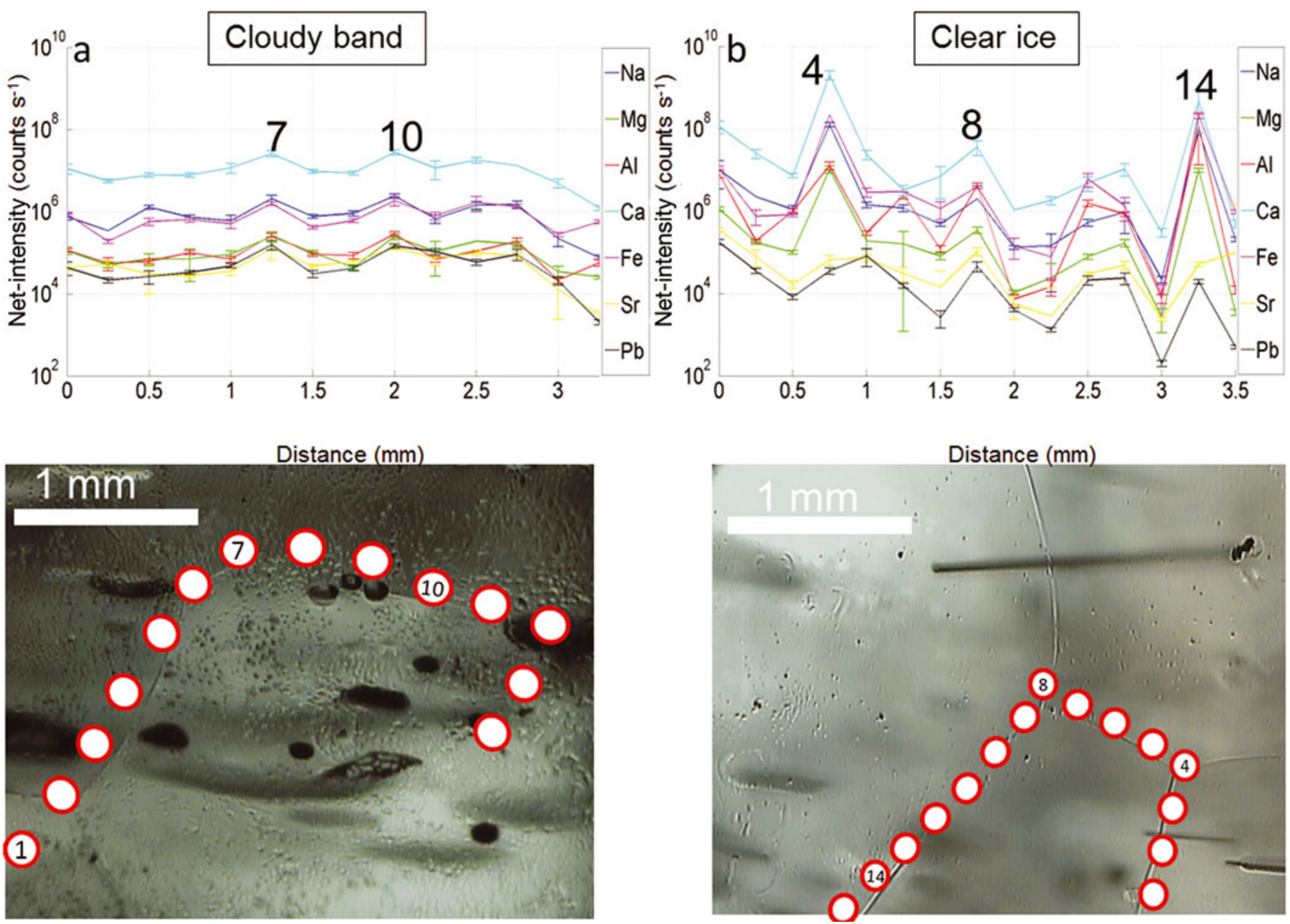

Fig. 15. Comparison of two chains-of-spots acquired along grain boundaries in cloudy bands (a) and clear ice (b) in NGRIP sample 4899 _B8 (2694.025-2694.075 m). (a) Chain of 14 spots, size $128 \mu \mathrm{m}$, spacing $150 \mu \mathrm{m}$. Intensity values are comparable with those acquired in grain interiors in Figures 5-10. (b) Chain of 15 spots, size $164 \mu \mathrm{m}$, spacing $200 \mu \mathrm{m}$. Intensity values are higher than those acquired in grain interiors in Figures 11-14 (note the $y$-axis scale up to $10^{10}$ ), with peaks that correspond to triple junctions. (Intensities with $164 \mu \mathrm{m}$ spots are nominally $\sim 1.7 \times$ higher than those at $128 \mu \mathrm{m}$.)

the inclination of the layering in the elemental maps is greater than is observed in the scan image $\left(30-60^{\circ}\right.$ and $\sim 30^{\circ}$ respectively).

Figures 17-19 show elemental mapping across a cloudy band at $\sim 2695 \mathrm{~m}$ depth. Concentrations of elements are high enough to also access elements like $\mathrm{Sr}$ and $\mathrm{Pb}$, with the exception of $\mathrm{Na}$, which shows relatively low concentration in the middle part, having higher concentration where the ice is clearer at the top. All the elements present similar maps showing that, within cloudy bands, elements do not lie preferentially on grain boundaries, even in areas where grain sizes are considerably smaller. Most of the variability within the band can be ascribed to different grains or different domains, which naturally can incorporate different amounts of impurities that seem to be evenly distributed within the grains.

The $\mathrm{Ca} / \mathrm{Al}$ ratio (Fig. 19) is more variable than the Fe/Al ratio, and also tends to differ between neighbouring grains, with values varying between 0 and 15 . This might represent a different input of particles, which even at the $\mathrm{mm}$ scale could distribute differently from grain to grain. $\mathrm{Ca} / \mathrm{Al}$ ratios and $\mathrm{Fe} / \mathrm{Al}$ obtained in this analysis (Table 2) are at least three times higher than the representative values of upper crust, and most probably result from a mix of dust from different sources located near some of the major Asian deserts such as the Gobi and Taklamakan. A clear component derived from Chinese loess could not be identified in this case.

The distribution of impurities observed in the samples suggests that at this depth of the NGRIP ice core grain boundaries do not always have high concentrations of soluble impurities, as was observed by Barnes and Wolff (2004) for Holocene ice and by Cullen and Baker (2000, 2001) for GISP2 and Byrd records. In fact, impurities tend to distribute themselves evenly between boundaries and bulk nuclei, as confirmed by profiles acquired over different cloudy bands and different core depths (Figs 5-9). When impurities are not abundant, as in clear ice, the data suggest that they tend to be allocated on boundaries and even more on junctions between grains.

From Eqn (3) we know that the smaller amount of impurities present in clear ice compared to cloudy bands should decrease the pinning effect and produce a more homogeneous distribution of impurities between boundaries and grain interiors. However, our data suggest that, in cloudy bands, the mobility of the grains is high enough to make the boundaries break away from impurities, which therefore can be homogeneously distributed between 


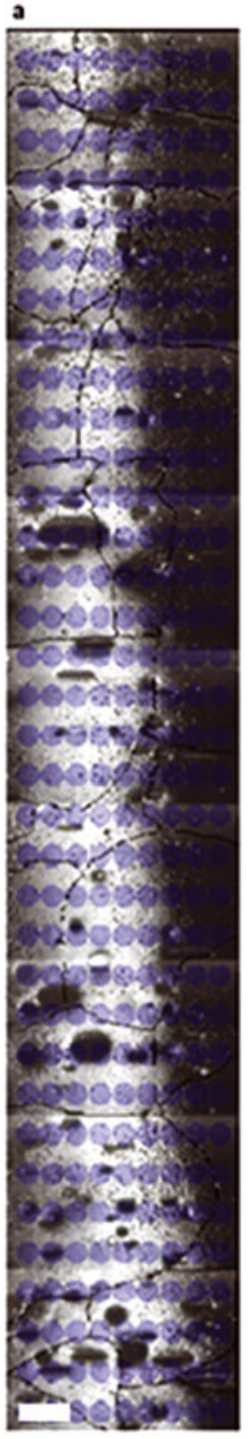

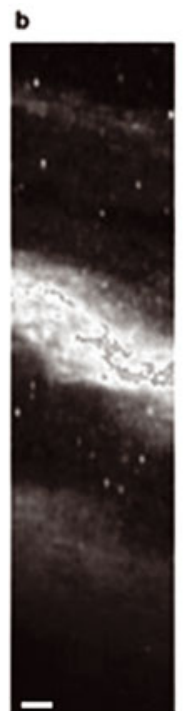
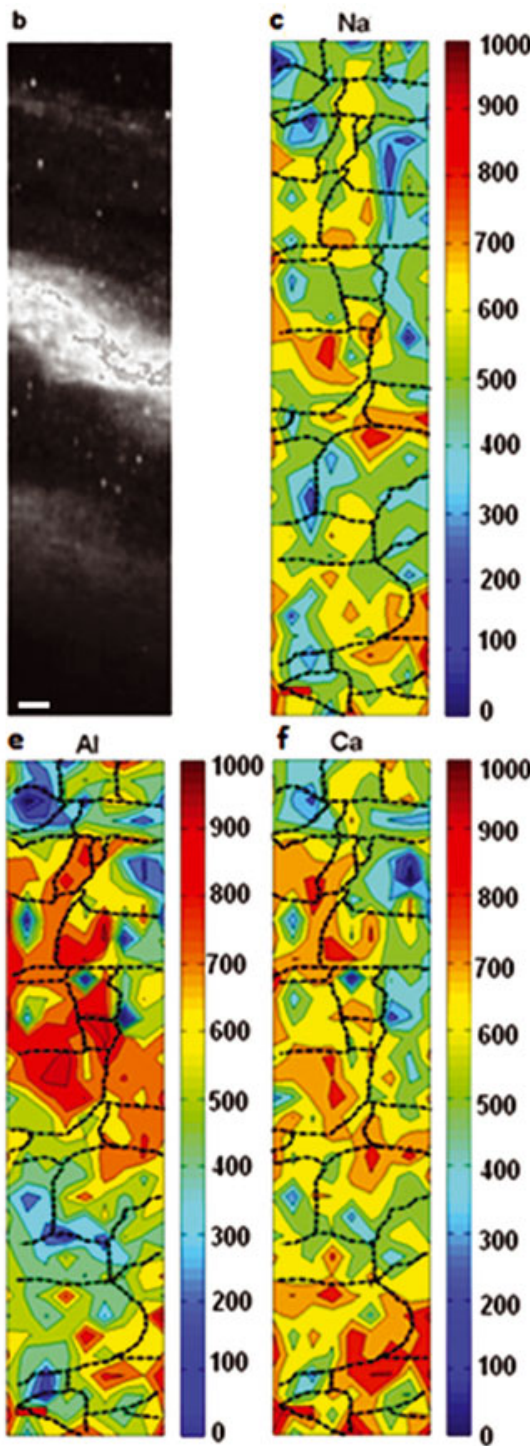

d $\mathrm{Mg}$

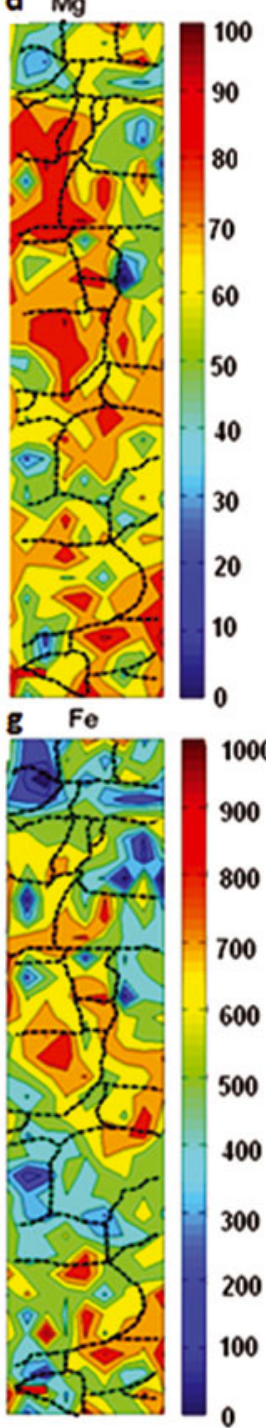

Net-intensity $\left(10^{3}\right.$ counts $\left.\mathrm{s}^{-1}\right)$

Fig. 16. (a) Picture of ice surface analysed as 2 -D grid with the corresponding laser spots $(9 \times 35$ spots, $280 \mu \mathrm{m}$ size, $300 \mu \mathrm{m}$ spacing; sample A7). (b) Scan image of the small section of the core analysed $(27 \mathrm{~mm} \times 6 \mathrm{~mm})$. (c-g) Major elements indicative of dust (Al, Ca, Fe) and sea salt ( $\mathrm{Na}, \mathrm{Mg}$ ) are shown; scale bar is $1 \mathrm{~mm}$. High intensities of elements (Al, Ca, Fe) match the cloudy band (shown in (b)) reasonably well. There is no clear correspondence of high intensities and grain boundaries, but elements seem rather to distribute differently from one grain to another, having extreme values in the interior parts of the grains and not near boundaries. The grain boundary net (dashed black line) is overlapped to the graphs. Depth interval is $2694.7-2694.65 \mathrm{~m}$.

boundaries and interiors. In clear ice, the force that drags boundaries of ice grains is not large enough to make the boundaries break away from the impurities, resulting in resolvable differences between grain boundaries and interiors of grains in terms of intensities. This may suggest that impurities in cloudy bands have a greater size than in clear ice, possibly originating from dust input, whereas in clear ice impurities may predominantly be in the form of soluble particles. This would increase the drag effect (again according to Eqn (3)) in clear ice and decrease it in cloudy bands. Further investigations of this effect in ice from various depths will be necessary to fully understand the distribution of impurities between grain boundaries and grain interiors.

The correlation between the layering visible on scan images and the impurity distribution is fairly well preserved, especially in elements like $\mathrm{Na}$ and $\mathrm{Fe}$, whereas for $\mathrm{Mg}$, $\mathrm{Al}$ and $\mathrm{Ca}$ the high-intensity zones sometimes exceed the corresponding area identifiable as a bright layer on the scan image.

\section{CONCLUSIONS}

The application of UV-laser ablation ICPMS analysis on ice cores allows mapping of impurities at a resolution well below $1 \mathrm{~mm}$, namely $<150-300 \mu \mathrm{m}$. All the elements show a signal/background ratio sufficient to resolve intensities at different spot sizes, although $\mathrm{Na}$ is challenging in clear ice. The vertical section analysed (Fig. 16) shows two complete seasonal cycles with a layering tilted by $\sim 30^{\circ}$. This is mimicked well by $\mathrm{Fe}$ and $\mathrm{Na}$ intensity variability across the section.

Soluble and insoluble impurities are evenly distributed between grains and grain domains, and impurities do not 


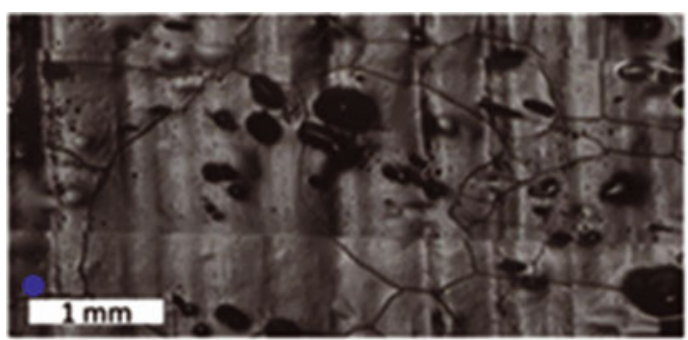

a
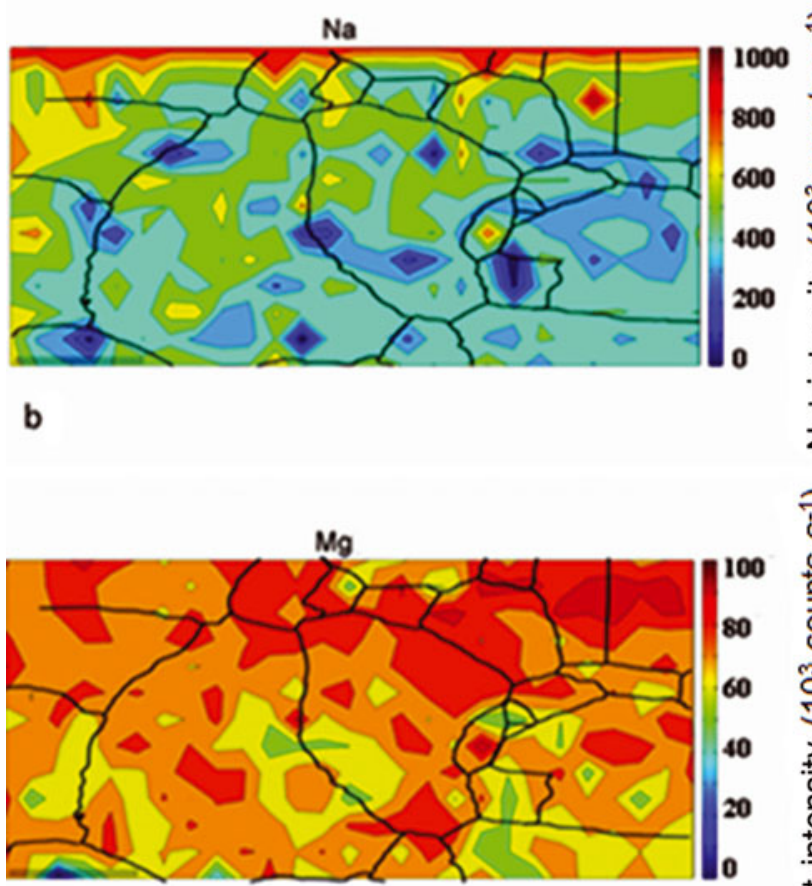

c

Fig. 17. (a) Image of the section analysed taken with the camera of the laser system. For size comparison a single spot is shown above the scale bar (sample 4900_A5). (b-d) Elemental variability over a $10 \mathrm{~mm} \times 5 \mathrm{~mm}$ area of NGRIP sample at depth of $2694.75-$ $2694.8 \mathrm{~m}$; scale bar is $1 \mathrm{~mm}$. Laser spot size is $164 \mu \mathrm{m}, 200 \mu \mathrm{m}$ spacing, repetition rate $20 \mathrm{~Hz}$. The grain boundary net (black lines) is overlapped to the image.

always show a clear tendency to distribute themselves along grain boundaries or triple junctions. Also in cases of reduced grain size the highest elemental concentrations can be found within the interiors of grains. However, in some cases, especially for clear ice, a strong relationship between grain boundaries or triple junctions and abundance of impurities is observed. This suggests that the harvesting of microinclusions acts differently in cloudy bands and clear ice, possibly because of a difference in particle size between clear ice and cloudy bands. However, further studies of the distribution of impurities between boundaries and grain interiors will be necessary to understand their interaction with grain mobility at various depths.

The comparison between scanned images of the core and LA-ICPMS derived elemental maps shows that Fe is the most reliable proxy for 'second phase particles' (i.e. dust), whereas $\mathrm{Na}$ and, to a lesser extent, $\mathrm{Mg}$ are the best proxies for soluble impurities (i.e. sea-salt proxies). Our $\mathrm{Ca} / \mathrm{Al}$ and $\mathrm{Fe} / \mathrm{Al}$ ratios are consistent with a mix of different dust

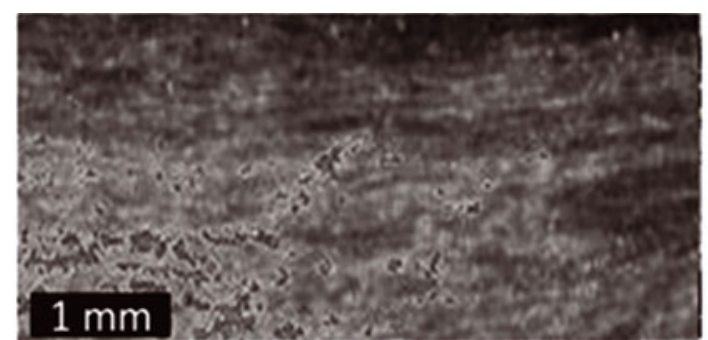

a

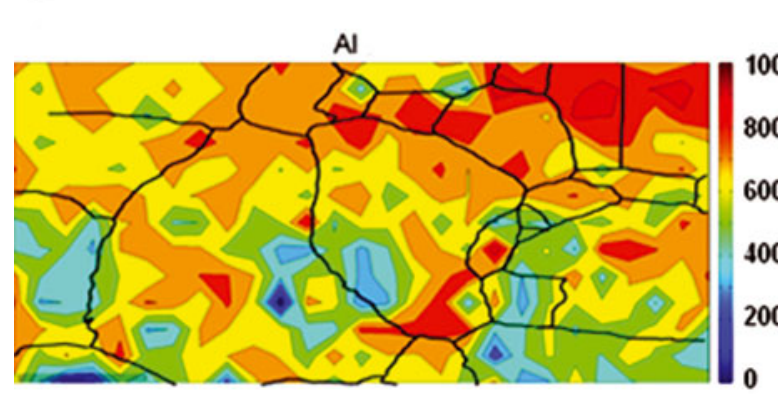

b
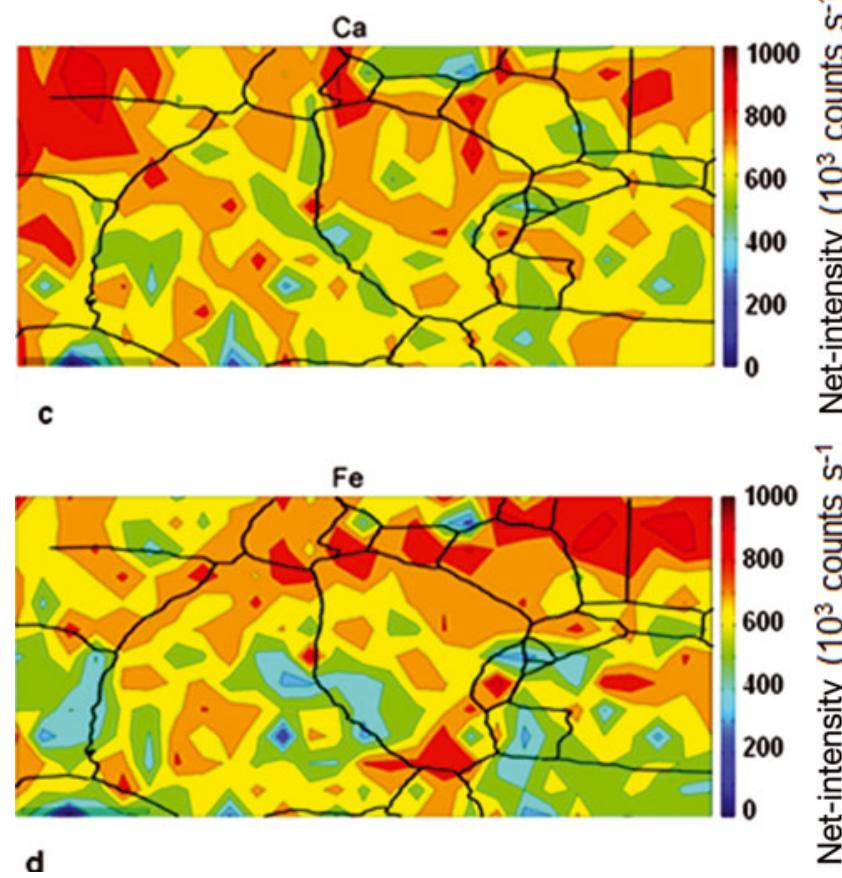

Fig. 18. (a) Crop of the section analysed taken by Svensson and others (2005). (b-d) Elemental variability over a $10 \mathrm{~mm} \times 5 \mathrm{~mm}$ area of NGRIP sample 4900_A5 at 2694.75-2694.8 m depth; scale bar is $1 \mathrm{~mm}$. Laser spot size is $164 \mu \mathrm{m}, 200 \mu \mathrm{m}$ spacing, repetition rate $20 \mathrm{~Hz}$. The grain boundary net (black lines) is overlapped to the image.

sources located among the major deserts of East Asia, such as the Gobi and Taklamakan.

\section{ACKNOWLEDGEMENTS}

We thank the Scientific Editor John W. Glen, Paul Vallelonga and Martin King for helpful discussions. Reviews by Sergio Faria and an anonymous reviewer helped to significantly improve the manuscript. A special acknowledgement is due to Jerry Morris (workshop), whose continued invaluable help made this work feasible. This work was funded by a RHUL studentship, Department Research Committee fund at 


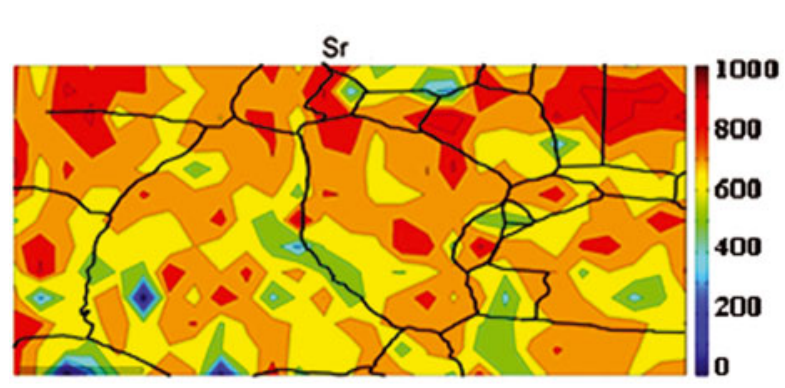

a

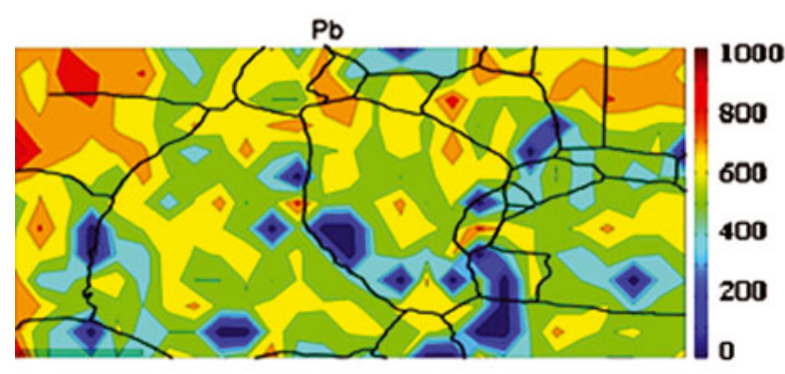

b

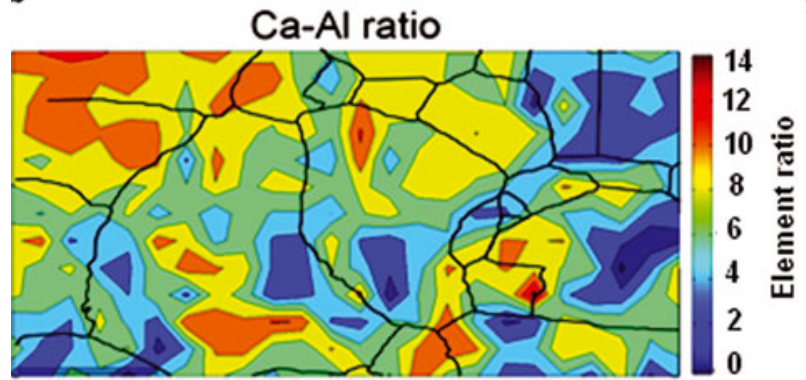

c

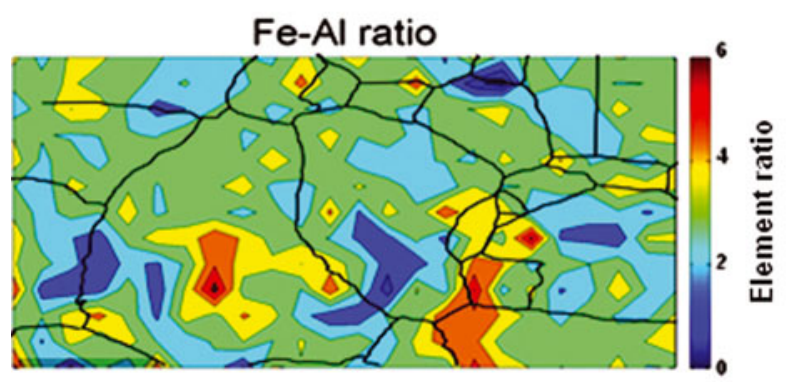

d

Fig. 19. (a) Sr elemental variability map. (b) Pb elemental variability map. (c) $\mathrm{Ca} / \mathrm{Al}$ ratio over the section analysed. (d) Fe/Al ratio over the section analysed. The grain boundary net (black lines) is overlapped to the image. Sample 4900_A5, depth interval 2694.75-2694.8 m.

RHUL, and the INTIMATE cost action-STSM fund, all bestowed upon Damiano Della Lunga.

\section{REFERENCES}

Alley RB and Woods GA (1996) Impurity influence on normal grain growth in the GISP2 ice core, Greenland. J. Glaciol., 42(141), 255-260

Alley RB, Perepezko JH and Bentley CR (1986) Grain growth in polar ice: I. Theory. J. Glaciol., 32(112), 415-424

Andersen KK and 11 others (2006) The Greenland Ice Core Chronology 2005, 15-42 ka. Part 1: constructing the time scale. Quat. Sci. Rev., 25(23-24), 3246-3257 (doi: 10.1016/ j.quascirev.2006.08.002)

Azuma N, Miyakoshi T, Yokoyama S and Takata M (2012) Impeding effect of air bubbles on normal grain growth of ice. J. Struct. Geol., 42, 184-193 (doi: 10.1016/j.jsg.2012.05.005)

Baker I and Cullen D (2003) SEM/EDS observations of impurities in polar ice: artifacts or not? J. Glaciol., 49(165), 184-190 (doi: 10.3189/172756503781830773)

Barnes PRF and Wolff EW (2004) Distribution of soluble impurities in cold glacial ice. J. Glaciol., 50(170), 311-324 (doi: 10.3189/ 172756504781829918)

Bigler M, Svensson A, Kettner E, Vallelonga P, Nielsen ME and Steffensen JP (2011) Optimization of high-resolution continuous flow analysis for transient climate signals in ice cores. Environ. Sci. Technol., 45(10), 4483-4489 (doi: 10.1021/es200118j)

Cullen D and Baker I (2000) Correspondence. The chemistry of grain boundaries in Greenland ice. J. Claciol., 46(155), 703-706 (doi: 10.3189/172756500781832783)

Cullen D and Baker I (2001) Observation of impurities in ice. Microsc. Res. Tech., 55(3), 198-207 (doi: 10.1002/jemt.10000)

Dahl-Jensen D and 8 others (2002) The NorthGRIP deep drilling programme. Ann. Glaciol., 35, 1-4 (doi: 10.3189/ 172756402781817275)

Durand G and 10 others (2006) Effect of impurities on grain growth in cold ice sheets. J. Geophys. Res., 111(F1), F01015 (doi: 10.1029/2005JF000320)

Durand G and 7 others (2009) Evolution of the texture along the EPICA Dome C ice core. In Hondoh T ed. Physics of ice core records II. (Supplement issue of Low Temperature Science 68) Institute of Low Temperature Science, Hokkaido University, Hokkaido, 91-106

Duval P and Lorius C (1980) Crystal size and climatic record down to the last ice age from Antarctic ice. Earth Planet. Sci. Lett., 48(1), 59-64 (doi: 10.1016/0012-821X(80)90170-3)

Duval P, Louchet F, Weiss J and Montagnat M (2012) On the role of long-range internal stresses on grain nucleation during dynamic discontinuous recrystallization. Mater. Sci. Eng. A, 546, 207-211 (doi: 10.1016/j.msea.2012.03.052)

Faria SH, Freitag J and Kipfstuhl S (2010) Polar ice structure and the integrity of ice-core paleoclimate records. Quat. Sci. Rev., 29(1-2), 338-351 (doi: 10.1016/j.quascirev.2009.10.016)

Faria SH, Weikusat I and Azuma N (2014) The microstructure of polar ice. Part II: state of the art. J. Struct. Geol., 61, 21-49 (doi: 10.1016/j.jsg.2013.11.003)

Fischer H, Siggaard-Andersen M-L, Ruth $U$, Röthlisberger R and Wolff E (2007) Glacial/interglacial changes in mineral dust and sea-salt records in polar ice cores: sources, transport, and deposition. Rev. Geophys., 45(RG10), RG1002 (doi: 10.1029/ 2005RG000192)

Fukazawa H, Sugiyama K, Mae S, Narita H and Hondoh T (1998) Acid ions at triple junction of Antarctic ice observed by Raman scattering. Geophys. Res. Lett., 25(15), 2845-2848 (doi: 10.1029/98GL02178)

Gow AJ (1969) On the rates of growth of grains and crystals in South Polar firn. J. Glaciol., 8(53), 241-252

Gow AJ and 6 others (1997) Physical and structural properties of the Greenland Ice Sheet Project 2 ice cores: a review. J. Geophys. Res., 102(C12), 26 559-26575 (doi: 10.1029/97JC00165)

Guillope M and Poirier JP (1979) Dynamic recrystallization during creep of single-crystalline halite: an experimental study. J. Geophys. Res., 84(B10), 5557-5567 (doi: 10.1029/ JB084iB10p05557)

Henderson P and Henderson GM (2009) The Cambridge handbook of earth science data. Cambridge University Press, Cambridge

Hörhold MW, Laepple T, Freitag J, Bigler M, Fischer $\mathrm{H}$ and Kipfstuhl S (2012) On the impact of impurities on the densification of polar firn. Earth Planet. Sci. Lett., 325-326, 93-99 (doi: 10.1016/j.epsl.2011.12.022)

lizuka Y, Takata M, Hondoh T and Fujii Y (2004) High-timeresolution profiles of soluble ions in the last glacial period of a 
Dome Fuji (Antarctica) deep ice core. Ann. Glaciol., 39, 452-456 (doi: 10.3189/172756404781814302)

lizuka Y and 6 others (2008) A relationship between ion balance and the chemical compounds of salt inclusions found in the Greenland Ice Core Project and Dome Fuji ice cores. J. Geophys. Res., 113(D7), D07303 (doi: 10.1029/2007JD009018)

Jochum KP and 11 others (2011) Determination of reference values for NIST SRM 610-617 glasses following ISO guidelines. Geostan. Geoanal. Res., 35(4), 397-429 (doi: 10.1111/j.1751908X.2011.00120.x)

Kipfstuhl S and 6 others (2006) Microstructure mapping: a new method for imaging deformation-induced microstructural features of ice on the grain scale. J. Glaciol., 52(178), 398-406 (doi: 10.3189/172756506781828647)

Kipfstuhl S and 8 others (2009) Evidence of dynamic recrystallization in polar firn. J. Geophys. Res., 114(B5), B05204 (doi: 10.1029/2008JB005583)

Lee YC, Yang X and Wenig M (2010) Transport of dusts from East Asian and non-East Asian sources to Hong Kong during dust storm related events 1996-2007. Atmos. Environ., 44(30), 3728-3738 (doi: 10.1016/j.atmosenv.2010.03.034)

Legrand MR and Delmas RJ (1988) Soluble impurities in four Antarctic ice cores over the last 30000 years. Ann. Glaciol., 10, 116-120

Li J, Jacka TH and Morgan V (1998) Crystal-size and microparticle record in the ice core from Dome Summit South, Law Dome, East Antarctica. Ann. Glaciol., 27, 343-348

Longerich HP, Jackson SE and Günther D (1996) Inter-laboratory note. Laser ablation inductively coupled plasma mass spectrometric transient signal data acquisition and analyte concentration calculation. J. Analy. Atom. Spectrom., 11(9), 899-904 (doi: 10.1039/JA9961100899)

McCurdy E and Woods G (2004) The application of collision/ reaction cell inductively coupled plasma mass spectrometry to multi-element analysis in variable sample matrices, using $\mathrm{He}$ as a non-reactive cell gas. J. Analy. Atom. Spectrom., 19(5), 607-615 (doi: 10.1039/B312250F)

Müller W, Shelley M, Miller P and Broude S (2009) Initial performance metrics of a new custom-designed ArF excimer LA-ICPMS system coupled to a two-volume laser-ablation cell. J. Analy. Atom. Spectrom., 24(2), 209-214 (doi: 10.1039/B805995K)

Müller W, Shelley JMG and Rasmussen SO (2011) Direct chemical analysis of frozen ice cores by UV-laser ablation ICPMS. J. Analy. Atom. Spectrom., 26(12), 2391-2395 (doi: 10.1039/ C1JA10242G)

Mulvaney R, Wolff EW and Oates K (1988) Sulphuric acid at grain boundaries in Antarctic ice. Nature, 331(6153), 247-249 (doi: 10.1038/331247a0)

North Greenland Ice Core Project (NorthGRIP) Members (2004) High-resolution record of Northern Hemisphere climate extending into the last interglacial period. Nature, 431(7005), 147-151 (doi: 10.1038/nature02805)

Obbard R and Baker I (2007) The microstructure of meteoric ice from Vostok, Antarctica. J. Glaciol., 53(180), 41-62 (doi: 10.3189/172756507781833901)

Ohno H, Igarashi A and Hondoh T (2005) Salt inclusions in polar ice core, location and chemical form of water-soluble impurities. Earth Planet. Sci. Lett., 232(1-2), 171-178 (doi: 10.1016/ j.epsl.2005.01.001)

Petit JR, Duval P and Lorius C (1987) Long-term climatic changes indicated by crystal growth in polar ice. Nature, 326(6108), 62-64 (doi: 10.1038/326062a0)

Rasmussen SO and 15 others (2006) A new Greenland ice core chronology for the last glacial termination. J. Geophys. Res., 111(D6), D06102 (doi: 10.1029/2005JD006079)
Reinhardt $\mathrm{H}$ and 6 others (2001) Laser ablation inductively coupled plasma mass spectrometry: a new tool for trace element analysis in ice cores. Fresenius' J. Anal. Chem., 370(5), 629-636 (doi: 10.1007/s002160100853)

Reinhardt H, Kriews M, Miller H, Lüdke C, Hoffmann E and Skole J (2003) Application of LA-ICP-MS in polar ice core studies. Anal. Bioanal. Chem., 375(8), 1265-1275 (doi: 10.1007/ s00216-003-1793-5)

Rempel AW, Waddington ED, Wettlaufer JS and Worster MG (2001) Possible displacement of the climate signal in ancient ice by premelting and anomalous diffusion. Nature, 411(6837), 568-571 (doi: 10.1038/35079043)

Rempel AW, Wettlaufer JS and Waddington ED (2002) Anomalous diffusion of multiple impurity species: predicted implications for the ice core climate records. J. Geophys. Res., 107(B12), 2330 (10.1029/2002JB001857)

Sakurai T and 6 others (2009) Direct observation of salts as microinclusions in the Greenland GRIP ice core. J. Glaciol., 55(193), 777-783 (doi: 10.3189/002214309790152483)

Sakurai T, Ohno H, Horikawa S, lizuka Y, Uchida T and Hondoh T (2010) A technique for measuring microparticles in polar ice using micro-Raman spectroscopy. Int. J. Spectrosc., 2010, 384956 (doi: 10.1155/2010/384956)

Steffensen JP (1997) The size distribution of microparticles from selected segments of the GRIP ice core representing different climatic periods. J. Geophys. Res., 102(C12), $26755-26763$

Stephenson PJ (1967) Some considerations of snow metamorphism in the Antarctic ice sheet in the light of ice crystal studies. In Oura $\mathrm{H}$ ed. Physics of snow and ice. Hokkaido University, Institute of Low Temperature Science, Sapporo, 725-740

Svensson A, Biscaye PE and Grousset FE (2000) Characterization of late glacial continental dust in the Greenland Ice Core Project ice core. J. Geophys. Res., 105(D4), 4637-4656 (doi: 10.1029/ 1999JD901093)

Svensson A and 7 others (2005) Visual stratigraphy of the North Greenland Ice Core Project (NorthGRIP) ice core during the last glacial period. J. Geophys. Res., 110(D2), D02108 (doi: 10.1029/2004JD005134)

Thorsteinsson T, Kipfstuhl J, Eicken H, Johnsen SJ and Fuhrer $\mathrm{K}$ (1995) Crystal size variations in Eemian-age ice from the GRIP ice core, central Greenland. Earth Planet. Sci. Lett., 131(3-4), 381-394 (doi: 10.1016/0012-821X(95)00031-7)

Thorsteinsson T, Kipfstuhl J and Miller H (1997) Textures and fabrics in the GRIP ice core. J. Geophys. Res., 102(C12), 26583-26599 (doi: 10.1029/97JC00161)

Vallelonga P and 12 others (2012) Duration of Greenland Stadial 22 and ice-gas $\Delta$ age from counting of annual layers in Greenland NGRIP ice core. Climate Past, 8(6), 1839-1847 (doi: 10.5194/cp-8-1839-2012)

Wang Y, Thorsteinsson T, Kipfstuhl J, Miller H, Dahl-Jensen D and Shoji $\mathrm{H}$ (2002) A vertical girdle fabric in the NorthGRIP deep ice core, North Greenland. Ann. Glaciol., 35, 515-520 (doi: 10.3189/172756402781817301)

Warren SG and Brandt RE (2008) Optical constants of ice from the ultraviolet to the microwave: a revised compilation. J. Geophys. Res., 113(D14), D14220 (doi: 10.1029/2007JD009744)

Weiss J, Vidot J, Gay M, Arnaud L, Duval P and Petit JR (2002) Dome Concordia ice microstructure: impurities effect on grain growth. Ann. Glaciol., 35, 552-558 (doi: 10.3189/ $172756402781816573)$

Weltje GJ and Tjallingii R (2008) Calibration of XRF core scanners for quantitative geochemical logging of sediment cores: theory and application. Earth Planet. Sci. Lett., 274(3-4), 423-438 (doi: 10.1016/j.epsl.2008.07.054) 